\title{
A Hybrid Iterative Scheme for a Maximal Monotone Operator and Two Countable Families of Relatively Quasi-Nonexpansive Mappings for Generalized Mixed Equilibrium and Variational Inequality Problems
}

\author{
Siwaporn Saewan and Poom Kumam \\ Department of Mathematics, Faculty of Science, King Mongkut's University of \\ Technology Thonburi (KMUTT), Bangmod, Bangkok 10140, Thailand \\ Correspondence should be addressed to Poom Kumam, poom.kum@kmutt.ac.th \\ Received 14 August 2010; Revised 30 September 2010; Accepted 10 October 2010 \\ Academic Editor: Douglas Robert Anderson
}

Copyright (C) 2010 S. Saewan and P. Kumam. This is an open access article distributed under the Creative Commons Attribution License, which permits unrestricted use, distribution, and reproduction in any medium, provided the original work is properly cited.

\begin{abstract}
We introduce a new hybrid iterative scheme for finding a common element of the set of common fixed points of two countable families of relatively quasi-nonexpansive mappings, the set of the variational inequality for an $\alpha$-inverse-strongly monotone operator, the set of solutions of the generalized mixed equilibrium problem and zeros of a maximal monotone operator in the framework of a real Banach space. We obtain a strong convergence theorem for the sequences generated by this process in a 2 uniformly convex and uniformly smooth Banach space. The results presented in this paper improve and extend some recent results.
\end{abstract}

\section{Introduction}

Let $E$ be a Banach space with norm $\|\cdot\|, C$ a nonempty closed convex subset of $E$, and let $E^{*}$ denote the dual of $E$. Let $\theta: C \times C \rightarrow \mathbb{R}$ be a bifunction, $\varphi: C \rightarrow \mathbb{R}$ be a real-valued function, and $B: C \rightarrow E^{*}$ a mapping. The generalized mixed equilibrium problem, is to find $x \in C$ such that

$$
\theta(x, y)+\langle B x, y-x\rangle+\varphi(y)-\varphi(x) \geq 0, \quad \forall y \in C
$$

The set of solutions to (1.1) is denoted by $\operatorname{GMEP}(\theta, B, \varphi)$, that is,

$$
\operatorname{GMEP}(\theta, B, \varphi)=\{x \in C: \theta(x, y)+\langle B x, y-x\rangle+\varphi(y)-\varphi(x) \geq 0, \forall y \in C\} .
$$


If $B \equiv 0$, the problem (1.1) reduces into the mixed equilibrium problem for $\theta$, denoted by $\operatorname{MEP}(\theta, \varphi)$, which is to find $x \in C$ such that

$$
\theta(x, y)+\varphi(y)-\varphi(x) \geq 0, \quad \forall y \in C
$$

If $\theta \equiv 0$, the problem (1.1) reduces into the mixed variational inequality of Browder type, denoted by $\operatorname{VI}(C, B, \varphi)$, which is to find $x \in C$ such that

$$
\langle B x, y-x\rangle+\varphi(y)-\varphi(x) \geq 0, \quad \forall y \in C
$$

If $B \equiv 0$ and $\varphi \equiv 0$ the problem (1.1) reduces into the equilibrium problem for $\theta$, denoted by $E P(\theta)$, which is to find $x \in C$ such that

$$
\theta(x, y) \geq 0, \quad \forall y \in C
$$

If $\theta \equiv 0$, the problem (1.3) reduces into the minimize problem, denoted by $\operatorname{Argmin}(\varphi)$, is to find $x \in C$ such that

$$
\varphi(y)-\varphi(x) \geq 0, \quad \forall y \in C
$$

The above formulation (1.4) was shown in [1] to cover monotone inclusion problems, saddle point problems, variational inequality problems, minimization problems, optimization problems, variational inequality problems, vector equilibrium problems, Nash equilibria in noncooperative games. In addition, there are several other problems, for example, the complementarity problem, fixed point problem and optimization problem, which can also be written in the form of an $E P(\theta)$. In other words, the $E P(\theta)$ is an unifying model for several problems arising in physics, engineering, science, optimization, economics, and so forth. In the last two decades, many papers have appeared in the literature on the existence of solutions of $\operatorname{EP}(\theta)$; see, for example, [1,2] and references therein. Some solution methods have been proposed to solve the $E P(\theta)$; see, for example, [1, 3-11] and references therein.

A Banach space $E$ is said to be strictly convex if $\|(x+y) / 2\|<1$ for all $x, y \in E$ with $\|x\|=\|y\|=1$ and $x \neq y$. Let $S(E)=\{x \in E:\|x\|=1\}$ be the unit sphere of $E$. Then a Banach space $E$ is said to be smooth if the limit

$$
\lim _{t \rightarrow 0} \frac{\|x+t y\|-\|x\|}{t}
$$

exists for each $x, y \in S(E)$. It is also said to be uniformly smooth if the limit exists uniformly for $x, y \in S(E)$. Let $E$ be a Banach space. The modulus of convexity of $E$ is the function $\delta:[0,2] \rightarrow$ $[0,1]$ defined by

$$
\delta(\varepsilon)=\inf \left\{1-\left\|\frac{x+y}{2}\right\|: x, y \in E,\|x\|=\|y\|=1,\|x-y\| \geq \varepsilon\right\} .
$$

A Banach space $E$ is uniformly convex if and only if $\delta(\varepsilon)>0$ for all $\varepsilon \in(0,2]$. Let $p$ be a fixed real number with $p \geq 2$. A Banach space $E$ is said to be $p$-uniformly convex if there exists 
a constant $c>0$ such that $\delta(\varepsilon) \geq c \varepsilon^{p}$ for all $\varepsilon \in[0,2]$; see $[12,13]$ for more details. Observe that every $p$-uniformly convex is uniformly convex. One should note that no Banach space is $p$-uniformly convex for $1<p<2$. It is well known that a Hilbert space is 2-uniformly convex, uniformly smooth. For each $p>1$, the generalized duality mapping $J_{p}: E \rightarrow 2^{E^{*}}$ is defined by $J_{p}(x)=\left\{x^{*} \in E^{*}:\left\langle x, x^{*}\right\rangle=\|x\|^{p},\left\|x^{*}\right\|=\|x\|^{p-1}\right\}$ for all $x \in E$. In particular, $J=J_{2}$ is called the normalized duality mapping. If $E$ is a Hilbert space, then $J=I$, where $I$ is the identity mapping.

A set valued mapping $T: E \rightrightarrows E^{*}$ with graph $G(T)=\left\{\left(x, x^{*}\right): x^{*} \in T x\right\}$, domain $D(T)=\{x \in E: T x \neq \emptyset\}$, and rang $R(T)=\cup\{T x: x \in D(T)\}$. $T$ is said to be monotone if $\left\langle x^{*}-y^{*}, x-y\right\rangle \geq 0$, whenever $x^{*} \in T x, y^{*} \in T y$. A monotone operator $T$ is said to be maximal monotone if its graph is not properly contained in the graph of any other monotone operator on the same space. We know that if $T$ is maximal monotone, then the solution set $T^{-1} 0=\{x \in D(T): 0 \in T x\}$ is closed and convex. It is knows that $T$ is a maximal monotone if and only if $R(J+r T)=E^{*}$ for all $r>0$ when $E$ is a reflexive, strictly convex and smooth Banach space (see Rockafellar [14]).

Let $E$ be a smooth, strictly convex and reflexive Banach space, let $C$ be a nonempty closed convex subset of $E$ and let $T: E \rightrightarrows E^{*}$ be a monotone operator satisfying $D(T) \subset C \subset$ $J^{-1}\left(\bigcap_{r>0} R(J+r T)\right)$. Then we define the resolvent $T$ by $J_{r} x=\{z \in D(T): J x \in J z+r T z\}$, for all $x \in E$. In other words, $J_{r}=(J+r T)^{-1} J$ for all $r>0$. $J_{r}$ is a single-valued mapping from $E$ to $D(T)$. Also, we know that $T^{-1} 0=F\left(J_{r}\right)$ for all $r>0$, where $F\left(J_{r}\right)$ is the set of all fixed points of $J_{r}$. We can define, for $r>0$, the Yosida approximation of $T$ by $T_{r} x=\left(J x-J J_{r} x\right) / r$ for all $x \in E$. We know that $T_{r} x \in T\left(J_{r} x\right)$ for all $r>0$ and $x \in E$.

It is also known that if $E$ is uniformly smooth, then $J$ is uniformly norm-to-norm continuous on each bounded subset of $E$. We consider the problem of finding:

$$
v \in E \quad \text { such that } 0 \in T v \text {, }
$$

where $T$ is an operator from $E$ into $E^{*}$. Such $v \in E$ is called a zero point of $T$. Such a problem contains numerous problems in economics, optimization and physics. When $T$ is a maximal monotone operator, a well-know method for solving (1.9) in a Hilbert space $H$ is the proximal point algorithm: $x_{1}=x \in H$ and,

$$
x_{n+1}=J_{r_{n}} x_{n}, \quad n=1,2,3, \ldots,
$$

where $\left\{r_{n}\right\} \subset(0, \infty)$ and $J_{r_{n}}=\left(I+r_{n} T\right)^{-1}$, then Rockafellar [15] proved that the sequence $\left\{x_{n}\right\}$ converges weakly to an element of $T^{-1} 0$. Let $E$ be a real Banach space and let $C$ be a nonempty closed convex subset of $E$ and $A: C \rightarrow E^{*}$ be an operator. The classical variational inequality problem for an operator $A$ is to find $\bar{x} \in C$ such that

$$
\langle A \bar{x}, y-\bar{x}\rangle \geq 0, \quad \forall y \in C
$$

The set of solution of (1.11) is denote by $\operatorname{VI}(A, C)$. Recall that let $A: C \rightarrow E^{*}$ be a mapping. 
Then $A$ is called

(i) monotone if

$$
\langle A x-A y, x-y\rangle \geq 0, \quad \forall x, y \in C
$$

(ii) $\alpha$-inverse-strongly monotone if there exists a constant $\alpha>0$ such that

$$
\langle A x-A y, x-y\rangle \geq \alpha\|A x-A y\|^{2}, \quad \forall x, y \in C .
$$

The class of inverse-strongly monotone mappings has been studied by many researchers to approximating a common fixed point; see $[6,7,16,17]$ for more details.

Let $C$ be a closed convex subset of $E$, a mapping $S: C \rightarrow C$ is said to be nonexpansive if $\|S x-S y\| \leq\|x-y\|$, for all $x, y \in C$. A point $x \in C$ is a fixed point of $S$ provided $S x=x$. Denote by $F(S)$ the set of fixed points of $S$; that is, $F(S)=\{x \in C: S x=x\}$.

Consider the functional defined by

$$
\phi(x, y)=\|x\|^{2}-2\langle x, J y\rangle+\|y\|^{2}, \quad \text { for } x, y \in E .
$$

Recall that a point $p$ in $C$ is said to be an asymptotic fixed point of $S$ [18] if $C$ contains a sequence $\left\{x_{n}\right\}$ which converges weakly to $p$ such that $\lim _{n \rightarrow \infty}\left\|x_{n}-S x_{n}\right\|=0$. The set of asymptotic fixed points of $S$ will be denoted by $\widetilde{F(S)}$. A mapping $S$ from $C$ into itself is said to be relatively nonexpansive [19-21] if $\widetilde{F(S)}=F(S)$ and $\phi(p, S x) \leq \phi(p, x)$ for all $x \in C$ and $p \in F(S)$. The asymptotic behavior of a relatively nonexpansive mapping was studied in [22-24]. $S$ is said to be $\phi$-nonexpansive, if $\phi(S x, S y) \leq \phi(x, y)$ for $x, y \in C$. $S$ is said to be relatively quasinonexpansive (or quasi- $\phi$-nonexpansive) if $F(S) \neq \emptyset$ and $\phi(p, S x) \leq \phi(p, x)$ for $x \in C$ and $p \in$ $F(S)$. We note that the class of relatively quasi-nonexpansive mappings is more general than the class of relatively nonexpansive mappings [22-26] which requires the strong restriction: $F(S)=\widetilde{F(S)}$.

Let $C$ be a nonempty closed convex subset of a Hilbert space $H$ and $P_{C}: H \rightarrow C$ is the metric projection of $H$ onto $C$, then $P_{C}$ is nonexpansive. This fact actually characterizes Hilbert spaces and consequently, it is not available in more general Banach spaces. In this connection, Alber [27] recently introduced a generalized projection $\Pi_{C}$ from $E$ in to $C$ as follows:

$$
\Pi_{C}(x)=\arg \min _{y \in C} \phi(y, x), \quad \forall x \in E .
$$

It is obvious from the definition of function $\phi$ that

$$
(\|y\|-\|x\|)^{2} \leq \phi(y, x) \leq(\|y\|+\|x\|)^{2}, \quad \forall x, y \in E .
$$

If $E$ is a Hilbert space, then $\phi(y, x)=\|y-x\|^{2}$ and $\Pi_{C}$ becomes the metric projection of $E$ onto $C$. Let $\Pi_{C}$ be the generalized projection from a smooth, strictly convex and reflexive Banach space $E$ onto a nonempty closed convex subset $C$ of $E$. Then, $\Pi_{C}$ is a closed relatively quasinonexpansive mapping from $E$ onto $C$ with $F\left(\Pi_{C}\right)=C$. On the author hand, the generalized 
projection $\Pi_{C}: E \rightarrow C$ is a map that assigns to an arbitrary point $x \in E$ the minimum point of the functional $\phi(x, y)$, that is, $\Pi_{C} x=\bar{x}$, where $\bar{x}$ is the solution to the minimization problem

$$
\phi(\bar{x}, x)=\inf _{y \in C} \phi(y, x)
$$

The existence and uniqueness of the operator $\Pi_{C}$ follows from the properties of the functional $\phi(y, x)$ and strict monotonicity of the mapping $J$ (see, e.g., [27-31]).

Remark 1.1. If $E$ is a reflexive, strictly convex and smooth Banach space, then for $x, y \in E$, $\phi(x, y)=0$ if and only if $x=y$. It is sufficient to show that if $\phi(x, y)=0$ then $x=y$. From (1.14), we have $\|x\|=\|y\|$. This implies that $\langle x, J y\rangle=\|x\|^{2}=\|J y\|^{2}$. From the definition of $J$, one has $J x=J y$. Therefore, we have $x=y$; see $[29,31]$ for more details.

In 2004, Matsushita and Takahashi [32] introduced the following iteration: a sequence $\left\{x_{n}\right\}$ defined by

$$
x_{n+1}=\Pi_{C} J^{-1}\left(\alpha_{n} J x_{n}+\left(1-\alpha_{n}\right) J T x_{n}\right),
$$

where the initial guess element $x_{0} \in C$ is arbitrary, $\left\{\alpha_{n}\right\}$ is a real sequence in $[0,1], T$ is a relatively nonexpansive mapping and $\Pi_{C}$ denotes the generalized projection from $E$ onto a closed convex subset $C$ of $E$. They proved that the sequence $\left\{x_{n}\right\}$ converges weakly to a fixed point of $T$.

In 2005, Matsushita and Takahashi [25] proposed the following hybrid iteration method (it is also called the $C Q$ method) with generalized projection for relatively nonexpansive mapping $T$ in a Banach space $E$ :

$$
\begin{gathered}
x_{0} \in C, \quad \text { chosen arbitrarily, } \\
y_{n}=J^{-1}\left(\alpha_{n} J x_{n}+\left(1-\alpha_{n}\right) J T x_{n}\right), \\
C_{n}=\left\{z \in C: \phi\left(z, y_{n}\right) \leq \phi\left(z, x_{n}\right)\right\}, \\
Q_{n}=\left\{z \in C:\left\langle x_{n}-z, J x_{0}-J x_{n}\right\rangle \geq 0\right\}, \\
x_{n+1}=\prod_{C_{n} \cap Q_{n}} x_{0} .
\end{gathered}
$$

They proved that $\left\{x_{n}\right\}$ converges strongly to $\Pi_{F(T)} x_{0}$, where $\Pi_{F(T)}$ is the generalized projection from $C$ onto $F(T)$. In 2008, Iiduka and Takahashi [33] introduced the following iterative scheme for finding a solution of the variational inequality problem for an inversestrongly monotone operator $A$ in a 2-uniformly convex and uniformly smooth Banach space $E: x_{1}=x \in C$ and

$$
x_{n+1}=\Pi_{C} J^{-1}\left(J x_{n}-\lambda_{n} A x_{n}\right)
$$

for every $n=1,2,3, \ldots$, where $\Pi_{C}$ is the generalized metric projection from $E$ onto $C, J$ is the duality mapping from $E$ into $E^{*}$ and $\left\{\lambda_{n}\right\}$ is a sequence of positive real numbers. They proved that the sequence $\left\{x_{n}\right\}$ generated by (1.20) converges weakly to some element of $\operatorname{VI}(A, C)$. 
Recently, Takahashi and Zembayashi [34, 35], studied the problem of finding a common element of the set of fixed points of a nonexpansive mapping and the set of solutions of an equilibrium problem in the framework of Banach spaces. In 2008, Cholamjiak [36], proved the following iteration

$$
\begin{gathered}
z_{n}=\Pi_{C} J^{-1}\left(J x_{n}-\lambda_{n} A x_{n}\right), \\
y_{n}=J^{-1}\left(\alpha_{n} J x_{n}+\beta_{n} J T x_{n}+\gamma_{n} J S z_{n}\right), \\
u_{n} \in C \text { such that } \theta\left(u_{n}, y\right)+\frac{1}{r_{n}}\left\langle y-u_{n}, J u_{n}-J y_{n}\right\rangle \geq 0, \quad \forall y \in C, \\
C_{n+1}=\left\{z \in C_{n}: \phi\left(z, u_{n}\right) \leq \phi\left(z, x_{n}\right)\right\}, \\
x_{n+1}=\prod_{C_{n+1}} x_{0},
\end{gathered}
$$

where $J$ is the duality mapping on $E$. Assume that $\left\{\alpha_{n}\right\},\left\{\beta_{n}\right\}$ and $\left\{\gamma_{n}\right\}$ are sequences in $[0,1]$ such that $\alpha_{n}+\beta_{n}+\gamma_{n}=1, \lim _{\inf _{n \rightarrow \infty}} \alpha_{n} \beta_{n}>0$ and $\lim _{\inf _{n \rightarrow \infty}} \alpha_{n} \gamma_{n}>0$. Then $\left\{x_{n}\right\}$ converges strongly to $q=\Pi_{F} x_{0}$, where $F:=F(T) \cap F(S) \cap E P(\theta) \cap \operatorname{VI}(A, C)$. In 2009, Wei et al. [37] proved the following iteration for two relatively nonexpansive mappings in a Banach space $E$ :

$$
\begin{gathered}
x_{0} \in C, \\
J z_{n}=\alpha_{n} J x_{n}+\left(1-\alpha_{n}\right) J T x_{n}, \\
J u_{n}=\beta_{n} J x_{n}+\left(1-\beta_{n}\right) J S z_{n}, \\
H_{n}=\left\{v \in C: \phi\left(v, u_{n}\right) \leq \beta_{n} \phi\left(v, x_{n}\right)+\left(1-\beta_{n}\right) \phi\left(v, z_{n}\right) \leq \phi\left(v, x_{n}\right)\right\}, \\
W_{n}=\left\{z \in C:\left\langle z-x_{n} J x_{0}-J x_{n}\right\rangle \leq 0\right\}, \\
x_{n+1}=\prod_{H_{n} \cap W_{n}} x_{0},
\end{gathered}
$$

if $\left\{\alpha_{n}\right\}$ and $\left\{\beta_{n}\right\}$ are sequences in $[0,1)$ such that $\alpha_{n} \leq 1-\delta_{1}$ and $\beta_{n} \leq 1-\delta_{2}$ for some $\delta_{1}, \delta_{2} \in(0,1)$, then $\left\{x_{n}\right\}$ generated by (1.22) converges strongly to a point $\prod_{\mathcal{F}:=F(T) \cap F(S)} x_{0}$. Where the mapping $\Pi_{\mp}$ of $E$ onto $F$ is the generalized projection operator. Inoue et al. [38] proved strong convergence theorem for finding a common element of the zero point set of a maximal monotone operator and the fixed point set of a relatively nonexpansive mapping by using the hybrid method. After that, Klin-eam et al. [2], extend Inoue et al. [38] to obtain the strong convergence theorem for finding a common element of the zero point set of a maximal monotone operator and the fixed point set of two relatively nonexpansive mappings in a Banach space by using a new hybrid method.

On the other hand, Nakajo et al. [39] introduced the following condition. Let $C$ be a nonempty closed convex subset of a Hilbert space $H$, let $\left\{S_{n}\right\}$ be a family of mappings of $C$ into itself with $F:=\bigcap_{n=1}^{\infty} F\left(S_{n}\right) \neq \emptyset$ and $\omega_{w}\left(z_{n}\right)$ denotes the set of all weak subsequential limits of a bounded sequence $\left\{z_{n}\right\}$ in $C .\left\{S_{n}\right\}$ is said to satisfy the NST-condition if for every bounded sequence $\left\{z_{n}\right\}$ in $C$,

$$
\lim _{n \rightarrow \infty}\left\|z_{n}-S_{n} z_{n}\right\|=0 \quad \text { implies that } \omega_{w}\left(z_{n}\right) \subset F .
$$


Recall that a mapping $S: C \rightarrow C$ is closed if for each $\left\{x_{n}\right\}$ in $C$, if $x_{n} \rightarrow x$ and $S x_{n} \rightarrow$ $y$, then $S x=y$. Let $\left\{S_{n}\right\}$ be a family of mappings of $C$ in to itself with $F:=\bigcap_{n=1}^{\infty} F\left(S_{n}\right) \neq \emptyset$, $\left\{S_{n}\right\}$ is said to satisfy the $(*)$-condition if for each bounded sequence $\left\{z_{n}\right\}$ in $C$,

$$
\lim _{n \rightarrow \infty}\left\|z_{n}-S_{n} z_{n}\right\|=0, \quad z_{n} \longrightarrow z \quad \text { imply } z \in F
$$

It follows directly from the definitions above that if $\left\{S_{n}\right\}$ satisfies NST-condition, then $\left\{S_{n}\right\}$ satisfies $(*)$-condition. If $S_{n} \equiv S$ and $S$ is closed, then $\left\{S_{n}\right\}$ satisfies $(*)$-condition (see [40] for more details).

In this paper, we introduce a new hybrid projection method for finding a common solution of the set of common fixed points of two countable families of relatively quasi nonexpansive mappings, the set of the variational inequality for an $\alpha$-inverse-strongly monotone operator, the set of solutions of the generalized mixed equilibrium problem and zeros of a maximal monotone operator in a real uniformly smooth and 2-uniformly convex Banach space.

\section{Preliminaries}

We also need the following lemmas for the proof of our main results.

Lemma 2.1 ( $\mathrm{Xu}$ [41]). If $\mathrm{E}$ be a 2-uniformly convex Banach space and $0<c \leq 1$, then for all $x, y \in E$, one has

$$
\|x-y\| \leq \frac{2}{c^{2}}\|J x-J y\|
$$

where $J$ is the normalized duality mapping of $E$.

The best constant $1 / c$ in lemma is called the 2-uniformly convex constant of $E$.

Lemma 2.2 (Chidume [42, Corollary 4.17 pages 36-37]). If E be a p-uniformly convex Banach space and let $p$ be a given real number with $p \geq 2$, then for all $x, y \in E, j_{x} \in J_{p} x$ and $j_{y} \in J_{p} y$

$$
\left\langle x-y, j_{x}-j_{y}\right\rangle \geq \frac{c^{p}}{2^{p-2} p}\|x-y\|^{p}
$$

where $J_{p}$ is the generalized duality mapping of $E$ and $1 / c$ is the p-uniformly convexity constant of $E$.

Lemma 2.3 (Kamimura and Takahashi [30]). Let E be a uniformly convex and smooth Banach space and let $\left\{x_{n}\right\}$ and $\left\{y_{n}\right\}$ be two sequences of $E$. If $\phi\left(x_{n}, y_{n}\right) \rightarrow 0$ and either $\left\{x_{n}\right\}$ or $\left\{y_{n}\right\}$ is bounded, then $\left\|x_{n}-y_{n}\right\| \rightarrow 0$. 
Lemma 2.4 (Alber [27]). Let $C$ be a nonempty closed convex subset of a smooth Banach space $E$ and $x \in E$. Then $x_{0}=\Pi_{C} x$ if and only if

$$
\left\langle x_{0}-y, J x-J x_{0}\right\rangle \geq 0, \quad \forall y \in C
$$

Lemma 2.5 (Alber [27]). Let $E$ be a reflexive, strictly convex and smooth Banach space, let $C$ be a nonempty closed convex subset of $E$ and let $x \in E$. Then

$$
\phi\left(y, \Pi_{C} x\right)+\phi\left(\Pi_{C} x, x\right) \leq \phi(y, x), \quad \forall y \in C .
$$

Lemma 2.6 (Qin et al. [9]). Let E be a real uniformly smooth and strictly convex Banach space, and $C$ be a nonempty closed convex subset of $E$. Let $S: C \rightarrow C$ be a relatively quasi-nonexpansive mapping. Then $F(S)$ is a closed convex subset of $C$.

Let $E$ be a reflexive, strictly convex, smooth Banach space and $J$ the duality mapping from $E$ into $E^{*}$. Then $J^{-1}$ is also single valued, one-to-one, surjective, and it is the duality mapping from $E^{*}$ into $E$. We make use of the following mapping $V$ studied in Alber [27]

$$
V\left(x, x^{*}\right)=\|x\|^{2}-2\left\langle x, x^{*}\right\rangle+\left\|x^{*}\right\|^{2}
$$

for all $x \in E$ and $x^{*} \in E^{*}$, that is, $V\left(x, x^{*}\right)=\phi\left(x, J^{-1} x^{*}\right)$.

Lemma 2.7 (Kohsaka and Takahashi [43, Lemma 3.2]). Let E be a reflexive, strictly convex smooth Banach space and let $V$ be as in (2.5). Then

$$
V\left(x, x^{*}\right)+2\left\langle J^{-1} x^{*}-x, y^{*}\right\rangle \leq V\left(x, x^{*}+y^{*}\right)
$$

for all $x \in E$ and $x^{*}, y^{*} \in E^{*}$.

Lemma 2.8 (Kohsaka and Takahashi [44]). Let E be a smooth, strictly convex and reflexive Banach space, let $C$ be a nonempty closed convex subset of $E$ and let $T: E \rightrightarrows E^{*}$ be a monotone operator satisfying $D(T) \subset C \subset J^{-1}\left(\bigcap_{r>0} R(J+r T)\right)$. Let $r>0$, let $J_{r}$ and $T_{r}$ be the resolvent and the Yosida approximation of $A$, respectively. Then the following hold:

(i) $\phi\left(u, J_{r} x\right)+\phi\left(J_{r} x, x\right) \leq \phi(u, x)$, for all $x \in C, u \in T^{-1} 0$;

(ii) $\left(J_{r} x, T_{r} x\right) \in T$, for all $x \in C$;

(iii) $F\left(J_{r}\right)=T^{-1} 0$.

Let $C$ be a nonempty closed convex subset of a Banach space $E$ and let $A$ be an inversestrongly monotone mapping of $C$ into $E^{*}$ which is said to be hemicontinuous if for all $x, y \in C$, the mapping $F$ of $[0,1]$ into $E^{*}$, defined by $F(t)=A(t x+(1-t) y)$, is continuous with respect to the weak* topology of $E^{*}$. We define by $N_{C}(v)$ the normal cone for $C$ at a point $v \in C$, that is,

$$
N_{C}(v)=\left\{x^{*} \in E^{*}:\left\langle v-y, x^{*}\right\rangle \geq 0, \forall y \in C\right\} .
$$


Lemma 2.9 (Rockafellar [14]). Let $C$ be a nonempty, closed convex subset of a Banach space E and A a monotone, hemicontinuous operator of $C$ into $E^{*}$. Let $U: E \rightrightarrows E^{*}$ be an operator defined as follows:

$$
U v= \begin{cases}A v+N_{C}(v), & v \in C \\ \emptyset, & \text { otherwise }\end{cases}
$$

Then $U$ is maximal monotone and $U^{-1} 0=V I(A, C)$.

For solving the equilibrium problem for a bifunction $\theta: C \times C \rightarrow \mathbb{R}$, let us assume that $\theta$ satisfies the following conditions:

(A1) $\theta(x, x)=0$ for all $x \in C$;

(A2) $\theta$ is monotone, that is, $\theta(x, y)+\theta(y, x) \leq 0$ for all $x, y \in C$;

(A3) for each $x, y, z \in C$,

$$
\lim _{t \downarrow 0} \theta(t z+(1-t) x, y) \leq \theta(x, y)
$$

(A4) for each $x \in C, y \mapsto \theta(x, y)$ is convex and lower semicontinuous.

For example, let $B$ be a continuous and monotone operator of $C$ into $E^{*}$ and define

$$
\theta(x, y)=\langle B x, y-x\rangle, \quad \forall x, y \in C
$$

Then, $\theta$ satisfies (A1) $-(\mathrm{A} 4)$.

The following result is in Takahashi and Zembayashi ([34, 35, Lemma 2.7]).

Lemma 2.10 (see [34, 35, Lemma 2.7]). Let $C$ be a nonempty closed convex subset of a smooth, strictly convex and reflexive Banach space $E$, let $\theta$ be a bifunction from $C \times C$ to $\mathbb{R}$ satisfying (A1)(A4), let $r>0$ and let $x \in E$. Then, there exists $z \in C$ such that

$$
\theta(z, y)+\frac{1}{r}\langle y-z, J z-J x\rangle \geq 0, \quad \forall y \in C
$$

Motivated by Combettes and Hirstoaga [4] in a Hilbert space and Takahashi and Zembayashi [34] in a Banach space, Zhang [45] obtain the following lemma. 
Lemma 2.11 (Zhang [45, Lemma 1.5]). Let $C$ be a nonempty closed convex subset of a smooth, strictly convex and reflexive Banach space E. Let $B: C \rightarrow E^{*}$ be a continuous and monotone mapping, $\varphi: C \rightarrow \mathbb{R}$ is convex and lower semicontinuous and $\theta$ be a bifunction from $C \times C$ to $\mathbb{R}$ satisfying (A1)-(A4). For $r>0$ and $x \in E$, then there exists $u \in C$ such that

$$
\theta(u, y)+\langle B u, y-u\rangle+\varphi(y)-\varphi(u)+\frac{1}{r}\langle y-u, J u-J x\rangle \geq 0, \quad \forall y \in C .
$$

Define a mapping $K_{r}: C \rightarrow C$ as follows:

$$
K_{r}(x)=\left\{u \in C: \theta(u, y)+\langle B u, y-u\rangle+\varphi(y)-\varphi(u)+\frac{1}{r}\langle y-u, J u-J x\rangle \geq 0, \forall y \in C\right\}
$$

for all $x \in C$. Then the followings hold:

(1) $K_{r}$ is single-valued;

(2) $K_{r}$ is firmly nonexpansive, that is, for all $x, y \in E,\left\langle K_{r} x-K_{r} y, J K_{r} x-J K_{r} y\right\rangle \leq\left\langle K_{r} x-\right.$ $\left.K_{r} y, J x-J y\right\rangle$

(3) $F\left(K_{r}\right)=\widetilde{F\left(K_{r}\right)}=\operatorname{GMEP}(\theta, B, \varphi)$;

(4) GMEP(', B,' ') is closed and convex;

(5) $\phi\left(p, K_{r} z\right)+\phi\left(K_{r} z, z\right) \leq \phi(p, z)$, for all $p \in F\left(K_{r}\right)$ and $z \in E$.

\section{Main Results}

In this section, by using the $(*)$-condition, we prove the new convergence theorems for finding a common element of the set of solutions of generalized mixed equilibrium problems, the set of fixed points of two countable families of relatively quasi-nonexpansive mappings, zeros of maximal monotone operators and the solution set of variational inequalities for an $\alpha$ inverse strongly monotone mapping in a 2-uniformly convex and uniformly smooth Banach space.

Theorem 3.1. Let $C$ be a nonempty closed and convex subset of a 2-uniformly convex and uniformly smooth Banach space $E$. Let $T: E \rightrightarrows E^{*}$ be a maximal monotone operator satisfying $D(T) \subset C$ and let $J_{r}=(J+r T)^{-1} J$ for all $r>0$, where $J$ is the duality mapping on $E$. Let $\theta$ be a bifunction from $C \times C$ to $\mathbb{R}$ satisfying (A1)-( A4), and let $\varphi: C \rightarrow \mathbb{R}$ be a proper lower semicontinuous and convex function. Let $A$ be an $\alpha$-inverse-strongly monotone mapping of $C$ into $E^{*}$ satisfy $\|A y\| \leq\|A y-A u\|$, for all $y \in C$ and $u \in V I(A, C) \neq \emptyset$ and let $B: C \rightarrow E^{*}$ be a continuous and monotone mapping. Let $S_{n}, T_{n}: C \rightarrow C$ be two families of relatively quasi-nonexpansive mappings with satisfy the $(*)$ condition such that

$$
\Theta:=\left(\bigcap_{n=1}^{\infty} F\left(S_{n}\right)\right) \cap\left(\bigcap_{n=1}^{\infty} F\left(T_{n}\right)\right) \cap T^{-1} 0 \cap \operatorname{GMEP}\left({ }^{\prime}, \mathrm{B},,^{\prime}\right) \cap V I(\mathrm{~A}, \mathrm{C}) \neq \emptyset
$$


For an initial point $x_{0} \in E$ with $x_{1}=\Pi_{C_{1}} x_{0}$ and $C_{1}=C$, we define the sequence $\left\{x_{n}\right\}$ as follows:

$$
\begin{gathered}
w_{n}=\Pi_{C} J^{-1}\left(J x_{n}-\lambda_{n} A x_{n}\right), \\
z_{n}=J^{-1}\left(\beta_{n} J x_{n}+\left(1-\beta_{n}\right) J T_{n} J_{r_{n}} w_{n}\right), \\
y_{n}=J^{-1}\left(\alpha_{n} J x_{n}+\left(1-\alpha_{n}\right) J S_{n} z_{n}\right), \\
u_{n} \in C \text { such that } \theta\left(u_{n}, y\right)+\left\langle B u_{n}, y-u_{n}\right\rangle+\varphi(y)-\varphi\left(u_{n}\right)+\frac{1}{r_{n}}\left\langle y-u_{n}, J u_{n}-J y_{n}\right\rangle \\
\geq 0, \quad \forall y \in C, \\
C_{n+1}=\left\{z \in C_{n}: \phi\left(z, u_{n}\right) \leq \phi\left(z, z_{n}\right) \leq \phi\left(z, x_{n}\right)\right\}, \\
x_{n+1}=\prod_{C_{n+1}} x_{0}, \quad \forall n \geq 1,
\end{gathered}
$$

where $\left\{\alpha_{n}\right\},\left\{\beta_{n}\right\}$ are sequences in $[0,1]$ and $\left\{r_{n}\right\} \subset[d, \infty)$ for some $d>0$ and $\left\{\lambda_{n}\right\} \subset[a, b]$ for some $a, b$ with $0<a<b<c^{2} \alpha / 2$, where $1 / c$ is the 2-uniformly convexity constant of $E$. If $\lim \inf _{n \rightarrow \infty}\left(1-\alpha_{n}\right)>0$ and $\lim _{\inf _{n \rightarrow \infty}}\left(1-\beta_{n}\right)>0$, then $\left\{x_{n}\right\}$ converges strongly to $p \in \Theta$, where $p=\Pi_{\Theta} x_{0}$.

Proof. We split the proof into seven steps.

Step 1. We first show that $C_{n+1}$ is closed and convex for each $n \geq 1$.

By Lemma 2.6, we know that $\left(\bigcap_{n=1}^{\infty} F\left(S_{n}\right)\right) \cap\left(\bigcap_{n=1}^{\infty} F\left(T_{n}\right)\right)$ is closed and convex. We also know that if $T^{-1} 0$ and $\operatorname{VI}(A, C)$ are closed and convex. From Lemma 2.11 (4), we have GMEP(', B, ') is closed and convex. Hence $\Theta:=\left(\bigcap_{n=1}^{\infty} F\left(S_{n}\right)\right) \cap\left(\bigcap_{n=1}^{\infty} F\left(T_{n}\right)\right) \cap T^{-1} 0 \cap$ $\operatorname{GMEP}\left({ }^{\prime}, \mathrm{B},{ }^{\prime}\right) \cap \operatorname{VI}(\mathrm{A}, \mathrm{C})$ is a nonempty, closed and convex subset of $C$. Consequently, $\Pi_{\Theta} x_{0}$ is well defined.

Next, we prove that $C_{n}$ is closed and convex for each $n \geq 1$. It is obvious that $C_{1}=C$ is closed and convex. Suppose that $C_{n}$ is closed and convex for each $n \in \mathbb{N}$. Since for any $z \in C_{n}$, we know $\phi\left(z, u_{n}\right) \leq \phi\left(z, x_{n}\right)$ is equivalent to

$$
2\left\langle z, J x_{n}-J u_{n}\right\rangle \leq\left\|x_{n}\right\|^{2}-\left\|u_{n}\right\|^{2} .
$$

So, $C_{n+1}$ is closed and convex.

Step 2. We show that $\Theta \subset C_{n}$ for all $n \geq 1$.

Next, we show by induction that $\Theta \subset C_{n}$ for all $n \in \mathbb{N}$. Indeed, let $u_{n}=K_{r_{n}} y_{n}$ and $v_{n}=J_{r_{n}} w_{n}$ for all $n \geq 1$. On the other hand, from Lemma 2.11 one has $K_{r_{n}}$ is relatively 
quasi-nonexpansive mapping and $\Theta \subset C_{1}=C$. Suppose that $\Theta \subset C_{n}$ for some $n \geq 1$. Let $q \in \Theta \subset C_{n}$. Since $S_{n}$ is relatively quasi-nonexpansive mapping, we have

$$
\begin{aligned}
\phi\left(q, y_{n}\right) & =\phi\left(q, J^{-1}\left(\alpha_{n} J x_{n}+\left(1-\alpha_{n}\right) J S_{n} z_{n}\right)\right) \\
& =\|q\|^{2}-2\left\langle q, \alpha_{n} J x_{n}+\left(1-\alpha_{n}\right) J S_{n} z_{n}\right\rangle+\left\|\alpha_{n} J x_{n}+\left(1-\alpha_{n}\right) J S_{n} z_{n}\right\|^{2} \\
& \leq\|q\|^{2}-2 \alpha_{n}\left\langle q, J x_{n}\right\rangle-2\left(1-\alpha_{n}\right)\left\langle q, J S_{n} z_{n}\right\rangle+\alpha_{n}\left\|x_{n}\right\|^{2}+\left(1-\alpha_{n}\right)\left\|S_{n} z_{n}\right\|^{2} \\
& =\alpha_{n} \phi\left(q, x_{n}\right)+\left(1-\alpha_{n}\right) \phi\left(q, S_{n} z_{n}\right) \\
& \leq \alpha_{n} \phi\left(q, x_{n}\right)+\left(1-\alpha_{n}\right) \phi\left(q, z_{n}\right)
\end{aligned}
$$

by nonexpansiveness of $J_{r_{n}}$ (see [31, Theorem 4.6.3, page 130]) and $T_{n}$ is relatively quasinonexpansive mappings, we also have

$$
\begin{aligned}
\phi\left(q, z_{n}\right) & =\phi\left(q, J^{-1}\left(\beta_{n} J x_{n}+\left(1-\beta_{n}\right) J T_{n} v_{n}\right)\right) \\
& =\|q\|^{2}-2\left\langle q, \beta_{n} J x_{n}+\left(1-\beta_{n}\right) J T_{n} v_{n}\right\rangle+\left\|\beta_{n} J x_{n}+\left(1-\beta_{n}\right) J T_{n} v_{n}\right\|^{2} \\
& \leq\|q\|^{2}-2 \beta_{n}\left\langle q, J x_{n}\right\rangle-2\left(1-\beta_{n}\right)\left\langle q, J T_{n} v_{n}\right\rangle+\beta_{n}\left\|x_{n}\right\|^{2}+\left(1-\beta_{n}\right)\left\|T_{n} v_{n}\right\|^{2} \\
& =\beta_{n} \phi\left(q, x_{n}\right)+\left(1-\beta_{n}\right) \phi\left(q, T_{n} v_{n}\right) \\
& \leq \beta_{n} \phi\left(q, x_{n}\right)+\left(1-\beta_{n}\right) \phi\left(q, v_{n}\right) \\
& =\beta_{n} \phi\left(q, x_{n}\right)+\left(1-\beta_{n}\right) \phi\left(q, J_{r_{n}} w_{n}\right) \\
& \leq \beta_{n} \phi\left(q, x_{n}\right)+\left(1-\beta_{n}\right) \phi\left(q, w_{n}\right) .
\end{aligned}
$$

So, it follows that

$$
\begin{aligned}
\phi\left(q, u_{n}\right) & =\phi\left(q, K_{r_{n}} y_{n}\right) \\
& \leq \phi\left(q, y_{n}\right) \\
& \leq \alpha_{n} \phi\left(q, x_{n}\right)+\left(1-\alpha_{n}\right) \phi\left(q, z_{n}\right), \\
& \leq \alpha_{n} \phi\left(q, x_{n}\right)+\left(1-\alpha_{n}\right)\left[\beta_{n} \phi\left(q, x_{n}\right)+\left(1-\beta_{n}\right) \phi\left(q, w_{n}\right)\right] .
\end{aligned}
$$


Abstract and Applied Analysis

It follows from Lemmas 2.5 and 2.7, that

$$
\begin{aligned}
\phi\left(q, w_{n}\right) & =\phi\left(q, \Pi_{C} J^{-1}\left(J x_{n}-\lambda_{n} A x_{n}\right)\right) \\
& \leq \phi\left(q, J^{-1}\left(J x_{n}-\lambda_{n} A x_{n}\right)\right) \\
& =V\left(q, J x_{n}-\lambda_{n} A x_{n}\right) \\
& \leq V\left(q,\left(J x_{n}-\lambda_{n} A x_{n}\right)+\lambda_{n} A x_{n}\right)-2\left\langle J^{-1}\left(J x_{n}-\lambda_{n} A x_{n}\right)-q, \lambda_{n} A x_{n}\right\rangle \\
& =V\left(q, J x_{n}\right)-2 \lambda_{n}\left\langle J^{-1}\left(J x_{n}-\lambda_{n} A x_{n}\right)-q, A x_{n}\right\rangle \\
& =\phi\left(q, x_{n}\right)-2 \lambda_{n}\left\langle x_{n}-q, A x_{n}\right\rangle+2\left\langle J^{-1}\left(J x_{n}-\lambda_{n} A x_{n}\right)-x_{n},-\lambda_{n} A x_{n}\right\rangle .
\end{aligned}
$$

Thus, since $q \in \operatorname{VI}(A, C)$ and $A$ is $\alpha$-inverse-strongly monotone, we have

$$
\begin{aligned}
-2 \lambda_{n}\left\langle x_{n}-q, A x_{n}\right\rangle & =-2 \lambda_{n}\left\langle x_{n}-q, A x_{n}-A q\right\rangle-2 \lambda_{n}\left\langle x_{n}-q, A q\right\rangle \\
& \leq-2 \lambda_{n}\left\langle x_{n}-q, A x_{n}-A q\right\rangle \\
& =-2 \alpha \lambda_{n}\left\|A x_{n}-A q\right\|^{2} .
\end{aligned}
$$

By Lemma 2.1 and the fact that $\|A y\| \leq\|A y-A u\|$ for all $y \in C$ and $u \in \Theta$, we obtain

$$
\begin{aligned}
2\left\langle J^{-1}\left(J x_{n}-\lambda_{n} A x_{n}\right)-x_{n},-\lambda_{n} A x_{n}\right\rangle & =2\left\langle J^{-1}\left(J x_{n}-\lambda_{n} A x_{n}\right)-J^{-1}\left(J x_{n}\right),-\lambda_{n} A x_{n}\right\rangle \\
& \leq 2\left\|J^{-1}\left(J x_{n}-\lambda_{n} A x_{n}\right)-J^{-1}\left(J x_{n}\right)\right\|\left\|\lambda_{n} A x_{n}\right\| \\
& \leq \frac{4}{c^{2}}\left\|J J^{-1}\left(J x_{n}-\lambda_{n} A x_{n}\right)-J J^{-1}\left(J x_{n}\right)\right\|\left\|\lambda_{n} A x_{n}\right\| \\
& =\frac{4}{c^{2}}\left\|J x_{n}-\lambda_{n} A x_{n}-J x_{n}\right\|\left\|\lambda_{n} A x_{n}\right\| \\
& =\frac{4}{c^{2}}\left\|\lambda_{n} A x_{n}\right\|^{2} \\
& =\frac{4}{c^{2}} \lambda_{n}^{2}\left\|A x_{n}\right\|^{2} \\
& \leq \frac{4}{c^{2}} \lambda_{n}^{2}\left\|A x_{n}-A q\right\|^{2} .
\end{aligned}
$$


Substituting (3.8) and (3.9) into (3.7), we have

$$
\begin{aligned}
\phi\left(q, w_{n}\right) & \leq \phi\left(q, x_{n}\right)-2 \alpha \lambda_{n}\left\|A x_{n}-A q\right\|^{2}+\frac{4}{c^{2}} \lambda_{n}^{2}\left\|A x_{n}-A q\right\|^{2} \\
& =\phi\left(q, x_{n}\right)+2 \lambda_{n}\left(\frac{2}{c^{2}} \lambda_{n}-\alpha\right)\left\|A x_{n}-A q\right\|^{2} \\
& \leq \phi\left(q, x_{n}\right) .
\end{aligned}
$$

Substituting (3.10) into (3.6), we get

$$
\phi\left(q, u_{n}\right) \leq \alpha_{n} \phi\left(q, x_{n}\right)+\left(1-\alpha_{n}\right)\left[\beta_{n} \phi\left(q, x_{n}\right)+\left(1-\beta_{n}\right) \phi\left(q, x_{n}\right)\right]=\phi\left(q, x_{n}\right) .
$$

This shows that $q \in C_{n+1}$ which implies that $\Theta \subset C_{n+1}$ and hence, $\Theta \subset C_{n}$ for all $n \geq 1$. This implies that the sequence $\left\{x_{n}\right\}$ is well defined.

Step 3. We prove that $\left\{x_{n}\right\}$ is bounded.

Since $x_{n}=\Pi_{C_{n}} x_{0}$ and $x_{n+1}=\Pi_{C_{n+1}} x_{0} \subset C_{n+1} \subset C_{n}$, we have

$$
\phi\left(x_{n}, x_{0}\right) \leq \phi\left(x_{n+1}, x_{0}\right), \quad \forall n \geq 1 .
$$

By Lemma 2.5, we get

$$
\begin{aligned}
\phi\left(x_{n}, x_{0}\right) & =\phi\left(\Pi_{C_{n}}\left(x_{0}\right), x_{0}\right) \\
& \leq \phi\left(p, x_{0}\right)-\phi\left(p, x_{n}\right) \\
& \leq \phi\left(p, x_{0}\right), \quad \forall p \in \Theta .
\end{aligned}
$$

From (3.12) and (3.13), then $\left\{\phi\left(x_{n}, x_{0}\right)\right\}$ are nondecreasing and bounded. So, we obtain that $\lim _{n \rightarrow \infty} \phi\left(x_{n}, x_{0}\right)$ exists. In particular, by $(1.16)$, the sequence $\left\{\left(\left\|x_{n}\right\|-\left\|x_{0}\right\|\right)^{2}\right\}$ is bounded. This implies $\left\{x_{n}\right\}$ is also bounded. So, we have $\left\{u_{n}\right\},\left\{z_{n}\right\},\left\{y_{n}\right\}$ and $\left\{w_{n}\right\}$ are bounded.

Step 4 . We show that $\left\{x_{n}\right\}$ is a Cauchy sequence in C. Since $x_{m}=\Pi_{C_{m}} x_{0} \in C_{m} \subset C_{n}$, for $m>n$, by Lemma 2.5, we have

$$
\begin{aligned}
\phi\left(x_{m}, x_{n}\right) & =\phi\left(x_{m}, \Pi_{C_{n}} x_{0}\right) \\
& \leq \phi\left(x_{m}, x_{0}\right)-\phi\left(\Pi_{C_{n}} x_{0}, x_{0}\right) \\
& =\phi\left(x_{m}, x_{0}\right)-\phi\left(x_{n}, x_{0}\right) .
\end{aligned}
$$

Taking $m, n \rightarrow \infty$, we have $\phi\left(x_{m}, x_{n}\right) \rightarrow 0$. From Lemma 2.3 , we get $\left\|x_{n}-x_{m}\right\| \rightarrow 0$. Hence $\left\{x_{n}\right\}$ is a Cauchy sequence and by the completeness of $E$ and the closedness of $C$, we can assume that there exists $p \in C$ such that $x_{n} \rightarrow p \in C$ as $n \rightarrow \infty$. 
Step 5. We show that $\left\|J u_{n}-J x_{n}\right\| \rightarrow 0$, as $n \rightarrow \infty$. We taking $m=n+1$ in Step 4, we also have

$$
\lim _{n \rightarrow \infty} \phi\left(x_{n+1}, x_{n}\right)=0
$$

From Lemma 2.3, that

$$
\lim _{n \rightarrow \infty}\left\|x_{n+1}-x_{n}\right\|=0
$$

Since $J$ is uniformly norm-to-norm continuous on bounded subsets of $E$, we have

$$
\lim _{n \rightarrow \infty}\left\|J x_{n+1}-J x_{n}\right\|=0
$$

Since $x_{n+1}=\Pi_{C_{n+1}} x_{0} \in C_{n+1} \subset C_{n}$ and the definition of $C_{n+1}$, we have

$$
\phi\left(x_{n+1}, u_{n}\right) \leq \phi\left(x_{n+1}, x_{n}\right) \quad \forall n \in \mathbb{N}
$$

By (3.15), we obtain

$$
\lim _{n \rightarrow \infty} \phi\left(x_{n+1}, u_{n}\right)=0
$$

Again applying Lemma 2.3, we get

$$
\lim _{n \rightarrow \infty}\left\|x_{n+1}-u_{n}\right\|=0
$$

From

$$
\begin{aligned}
\left\|u_{n}-x_{n}\right\| & =\left\|u_{n}-x_{n+1}+x_{n+1}-x_{n}\right\| \\
& \leq\left\|u_{n}-x_{n+1}\right\|+\left\|x_{n+1}-x_{n}\right\|
\end{aligned}
$$

It follows that

$$
\lim _{n \rightarrow \infty}\left\|u_{n}-x_{n}\right\|=0
$$

Since $J$ is uniformly norm-to-norm continuous on bounded subsets of $E$, we also have

$$
\lim _{n \rightarrow \infty}\left\|J u_{n}-J x_{n}\right\|=0
$$


Step 6. We will show that $x_{n} \rightarrow p \in \Theta$, where

$$
\Theta:=\left(\bigcap_{n=1}^{\infty} F\left(T_{n}\right)\right) \cap\left(\bigcap_{n=1}^{\infty} F\left(S_{n}\right)\right) \cap \operatorname{GMEP}\left({ }^{\prime}, \mathrm{B},{ }^{\prime}\right) \cap \mathrm{VI}(\mathrm{A}, \mathrm{C}) \cap \mathrm{T}^{-1} 0 .
$$

(a) We show that $x_{n} \rightarrow p \in\left(\bigcap_{n=1}^{\infty} F\left(T_{n}\right)\right) \cap\left(\bigcap_{n=1}^{\infty} F\left(S_{n}\right)\right)$. From definition of $C_{n+1}$, for any $z \in C_{n}$, we have

$$
\phi\left(z, z_{n}\right) \leq \phi\left(z, x_{n}\right)
$$

Since $x_{n+1}=\prod_{C_{n+1}} x_{0} \in C_{n+1}$, we get $\phi\left(x_{n+1}, z_{n}\right) \leq \phi\left(x_{n+1}, x_{n}\right)$. It follows from (3.15), that

$$
\lim _{n \rightarrow \infty} \phi\left(x_{n+1}, z_{n}\right)=0
$$

again from Lemma 2.3, that

$$
\lim _{n \rightarrow \infty}\left\|x_{n+1}-z_{n}\right\|=0
$$

it follows that since $J$ is uniformly norm-to-norm continuous, we also have

$$
\lim _{n \rightarrow \infty}\left\|J x_{n+1}-J z_{n}\right\|=0 .
$$

Since

$$
\left\|z_{n}-x_{n}\right\| \leq\left\|z_{n}-x_{n+1}\right\|+\left\|x_{n+1}-x_{n}\right\|
$$

from (3.16) and (3.27), we also have

$$
\lim _{n \rightarrow \infty}\left\|z_{n}-x_{n}\right\|=0 .
$$

Since $J$ is uniformly norm-to-norm continuous, we obtain

$$
\lim _{n \rightarrow \infty}\left\|J z_{n}-J x_{n}\right\|=0 .
$$


From (3.4), (3.5) and (3.10), we get $\phi\left(p, y_{n}\right) \leq \phi\left(p, x_{n}\right)$. By Lemma 2.11 (5) and $u_{n}=K_{r_{n}} y_{n}$, we observe that

$$
\begin{aligned}
\phi\left(u_{n}, y_{n}\right) & =\phi\left(K_{r_{n}} y_{n}, y_{n}\right) \\
& \leq \phi\left(p, y_{n}\right)-\phi\left(p, K_{r_{n}} y_{n}\right) \\
& \leq \phi\left(p, x_{n}\right)-\phi\left(p, K_{r_{n}} y_{n}\right) \\
& =\phi\left(p, x_{n}\right)-\phi\left(p, u_{n}\right) \\
& =\|p\|^{2}-2\left\langle p, J x_{n}\right\rangle+\left\|x_{n}\right\|^{2}-\left(\|p\|^{2}-2\left\langle p, J u_{n}\right\rangle+\left\|u_{n}\right\|^{2}\right) \\
& =\left\|x_{n}\right\|^{2}-\left\|u_{n}\right\|^{2}-2\left\langle p, J x_{n}-J u_{n}\right\rangle \\
& \leq\left\|x_{n}-u_{n}\right\|\left(\left\|x_{n}\right\|+\left\|u_{n}\right\|\right)+2\|p\|\left\|J x_{n}-J u_{n}\right\| .
\end{aligned}
$$

Since $\left\{x_{n}\right\},\left\{y_{n}\right\}$ and $\left\{u_{n}\right\}$ are bounded, it follows from (3.22), (3.23), and Lemma 2.3, we also have

$$
\lim _{n \rightarrow \infty}\left\|u_{n}-y_{n}\right\|=0
$$

Since $J$ is uniformly norm-to-norm continuous, we have

$$
\lim _{n \rightarrow \infty}\left\|J u_{n}-J y_{n}\right\|=0
$$

By using the triangle inequality, we obtain

$$
\begin{aligned}
\left\|x_{n+1}-y_{n}\right\| & =\left\|x_{n+1}-u_{n}+u_{n}-y_{n}\right\| \\
& \leq\left\|x_{n+1}-u_{n}\right\|+\left\|u_{n}-y_{n}\right\| .
\end{aligned}
$$

By (3.20) and (3.33), we get

$$
\lim _{n \rightarrow \infty}\left\|x_{n+1}-y_{n}\right\|=0
$$

Since $J$ is uniformly norm-to-norm continuous, we obtain

$$
\lim _{n \rightarrow \infty}\left\|J x_{n+1}-J y_{n}\right\|=0
$$

Since

$$
\left\|y_{n}-z_{n}\right\| \leq\left\|y_{n}-x_{n+1}\right\|+\left\|x_{n+1}-z_{n}\right\|
$$


From (3.27) and (3.36), we have

$$
\lim _{n \rightarrow \infty}\left\|y_{n}-z_{n}\right\|=0
$$

Since $J$ is uniformly norm-to-norm continuous, we also have

$$
\lim _{n \rightarrow \infty}\left\|J y_{n}-J z_{n}\right\|=0
$$

From (3.2), we get

$$
\begin{aligned}
\left\|J y_{n}-J z_{n}\right\| & =\left\|\alpha_{n}\left(J x_{n}-J z_{n}\right)+\left(1-\alpha_{n}\right)\left(J S_{n} z_{n}-J z_{n}\right)\right\| \\
& =\left\|\left(1-\alpha_{n}\right)\left(J S_{n} z_{n}-J z_{n}\right)-\alpha_{n}\left(J z_{n}-J x_{n}\right)\right\| \\
& \geq\left(1-\alpha_{n}\right)\left\|J S_{n} z_{n}-J z_{n}\right\|-\alpha_{n}\left\|J z_{n}-J x_{n}\right\|,
\end{aligned}
$$

and hence

$$
\left(1-\alpha_{n}\right)\left\|J S_{n} z_{n}-J z_{n}\right\| \leq\left\|J y_{n}-J z_{n}\right\|+\alpha_{n}\left\|J z_{n}-J x_{n}\right\|
$$

it follows that

$$
\left\|J S_{n} z_{n}-J z_{n}\right\| \leq \frac{1}{1-\alpha_{n}}\left(\left\|J y_{n}-J z_{n}\right\|+\alpha_{n}\left\|J z_{n}-J x_{n}\right\|\right)
$$

Since $\lim \inf _{n \rightarrow \infty}\left(1-\alpha_{n}\right)>0$, (3.31) and (3.40), one has $\lim _{n \rightarrow \infty}\left\|J S_{n} z_{n}-J z_{n}\right\|=0$. Since $J^{-1}$ is uniformly norm-to-norm continuous, we get

$$
\lim _{n \rightarrow \infty}\left\|S_{n} z_{n}-z_{n}\right\|=0
$$

Since $\left\|x_{n}-z_{n}\right\| \rightarrow 0$ and $x_{n} \rightarrow p$, then we get $z_{n} \rightarrow p$, hence it follows from (*)-condition, that $p \in \bigcap_{n=1}^{\infty} F\left(S_{n}\right)$.

Since $v_{n}=J_{r_{n}} w_{n}$, we compute

$$
\begin{aligned}
\left\|J x_{n+1}-J z_{n}\right\| & =\left\|J x_{n+1}-\left(\beta_{n} J x_{n}+\left(1-\beta_{n}\right) J T_{n} v_{n}\right)\right\| \\
& =\left\|\beta_{n} J x_{n+1}-\beta_{n} J x_{n}+\left(1-\beta_{n}\right) J x_{n+1}-\left(1-\beta_{n}\right) J T_{n} v_{n}\right\| \\
& =\left\|\beta_{n}\left(J x_{n+1}-J x_{n}\right)+\left(1-\beta_{n}\right)\left(J x_{n+1}-J T_{n} v_{n}\right)\right\| \\
& =\left\|\left(1-\beta_{n}\right)\left(J x_{n+1}-J T_{n} v_{n}\right)-\beta_{n}\left(J x_{n}-J x_{n+1}\right)\right\| \\
& \geq\left(1-\beta_{n}\right)\left\|J x_{n+1}-J T_{n} v_{n}\right\|-\beta_{n}\left\|J x_{n}-J x_{n+1}\right\|
\end{aligned}
$$


and hence

$$
\left\|J x_{n+1}-J T_{n} v_{n}\right\| \leq \frac{1}{1-\beta_{n}}\left(\left\|J x_{n+1}-J z_{n}\right\|+\beta_{n}\left\|J x_{n}-J x_{n+1}\right\|\right) .
$$

From (3.17), (3.28) and $\lim \inf _{n \rightarrow \infty}\left(1-\beta_{n}\right)>0$, we obtain that

$$
\lim _{n \rightarrow \infty}\left\|J x_{n+1}-J T_{n} v_{n}\right\|=0
$$

Since $J^{-1}$ is uniformly norm-to-norm continuous on bounded sets, we have

$$
\lim _{n \rightarrow \infty}\left\|x_{n+1}-T_{n} v_{n}\right\|=0
$$

Using the triangle inequality, we have

$$
\begin{aligned}
\left\|x_{n}-T_{n} v_{n}\right\| & =\left\|x_{n}-x_{n+1}+x_{n+1}-T_{n} v_{n}\right\| \\
& \leq\left\|x_{n}-x_{n+1}\right\|+\left\|x_{n+1}-T_{n} v_{n}\right\| .
\end{aligned}
$$

From (3.16) and (3.48), we have

$$
\lim _{n \rightarrow \infty}\left\|x_{n}-T_{n} v_{n}\right\|=0
$$

On the other hand, for $q \in \Theta$, we note that

$$
\begin{aligned}
\phi\left(q, x_{n}\right)-\phi\left(q, u_{n}\right) & =\left\|x_{n}\right\|^{2}-\left\|u_{n}\right\|^{2}-2\left\langle q, J x_{n}-J u_{n}\right\rangle \\
& \leq\left\|x_{n}-u_{n}\right\|\left(\left\|x_{n}\right\|+\left\|u_{n}\right\|\right)+2\|q\|\left\|J x_{n}-J u_{n}\right\| .
\end{aligned}
$$


Since $\left\{x_{n}\right\}$ and $\left\{u_{n}\right\}$ are bounded, it follows from $\left\|x_{n}-u_{n}\right\| \rightarrow 0$ and $\left\|J x_{n}-J u_{n}\right\| \rightarrow 0$, that

$$
\phi\left(q, x_{n}\right)-\phi\left(q, u_{n}\right) \longrightarrow 0
$$

Furthermore, from (3.4), (3.5), (3.6) and (3.10), that

$$
\begin{aligned}
\phi\left(q, u_{n}\right) \leq & \phi\left(q, y_{n}\right) \\
\leq & \alpha_{n} \phi\left(q, x_{n}\right)+\left(1-\alpha_{n}\right) \phi\left(q, z_{n}\right) \\
\leq & \alpha_{n} \phi\left(q, x_{n}\right)+\left(1-\alpha_{n}\right)\left[\beta_{n} \phi\left(q, x_{n}\right)+\left(1-\beta_{n}\right) \phi\left(q, w_{n}\right)\right] \\
= & \alpha_{n} \phi\left(q, x_{n}\right)+\left(1-\alpha_{n}\right) \beta_{n} \phi\left(q, x_{n}\right)+\left(1-\alpha_{n}\right)\left(1-\beta_{n}\right) \phi\left(q, w_{n}\right) \\
\leq & \alpha_{n} \phi\left(q, x_{n}\right)+\left(1-\alpha_{n}\right) \beta_{n} \phi\left(q, x_{n}\right) \\
& +\left(1-\alpha_{n}\right)\left(1-\beta_{n}\right)\left[\phi\left(q, x_{n}\right)-2 \lambda_{n}\left(\alpha-\frac{2}{c^{2}} \lambda_{n}\right)\left\|A x_{n}-A q\right\|^{2}\right] \\
= & \alpha_{n} \phi\left(q, x_{n}\right)+\left(1-\alpha_{n}\right) \beta_{n} \phi\left(q, x_{n}\right)+\left(1-\alpha_{n}\right)\left(1-\beta_{n}\right) \phi\left(q, x_{n}\right) \\
& -\left(1-\alpha_{n}\right)\left(1-\beta_{n}\right) 2 \lambda_{n}\left(\alpha-\frac{2}{c^{2}} \lambda_{n}\right)\left\|A x_{n}-A q\right\|^{2} \\
= & \phi\left(q, x_{n}\right)-\left(1-\alpha_{n}\right)\left(1-\beta_{n}\right) 2 \lambda_{n}\left(\alpha-\frac{2}{c^{2}} \lambda_{n}\right)\left\|A x_{n}-A q\right\|^{2},
\end{aligned}
$$

and hence

$$
\begin{aligned}
2 a\left(\alpha-\frac{2 b}{c^{2}}\right)\left\|A x_{n}-A q\right\|^{2} & \leq 2 \lambda_{n}\left(\alpha-\frac{2}{c^{2}} \lambda_{n}\right)\left\|A x_{n}-A q\right\|^{2} \\
& \leq \frac{1}{\left(1-\alpha_{n}\right)\left(1-\beta_{n}\right)}\left(\phi\left(q, x_{n}\right)-\phi\left(q, u_{n}\right)\right) .
\end{aligned}
$$

From (3.52), $\lim \inf _{n \rightarrow \infty}\left(1-\alpha_{n}\right)>0$ and $\lim \inf _{n \rightarrow \infty}\left(1-\beta_{n}\right)>0$, obtain that

$$
\lim _{n \rightarrow \infty}\left\|A x_{n}-A q\right\|=0
$$


From Lemmas 2.5, 2.7, and (3.9), we compute

$$
\begin{aligned}
\phi\left(x_{n}, w_{n}\right) & =\phi\left(x_{n}, \Pi_{C} J^{-1}\left(J x_{n}-\lambda_{n} A x_{n}\right)\right) \\
& \leq \phi\left(x_{n}, J^{-1}\left(J x_{n}-\lambda_{n} A x_{n}\right)\right) \\
& =V\left(x_{n}, J x_{n}-\lambda_{n} A x_{n}\right) \\
& \leq V\left(x_{n},\left(J x_{n}-\lambda_{n} A x_{n}\right)+\lambda_{n} A x_{n}\right)-2\left\langle J^{-1}\left(J x_{n}-\lambda_{n} A x_{n}\right)-x_{n}, \lambda_{n} A x_{n}\right\rangle \\
& =\phi\left(x_{n}, x_{n}\right)+2\left\langle J^{-1}\left(J x_{n}-\lambda_{n} A x_{n}\right)-x_{n},-\lambda_{n} A x_{n}\right\rangle \\
& =2\left\langle J^{-1}\left(J x_{n}-\lambda_{n} A x_{n}\right)-x_{n},-\lambda_{n} A x_{n}\right\rangle \\
& \leq \frac{4 \lambda_{n}^{2}}{c^{2}}\left\|A x_{n}-A q\right\|^{2} \\
& \leq \frac{4 b^{2}}{c^{2}}\left\|A x_{n}-A q\right\|^{2} .
\end{aligned}
$$

Applying Lemma 2.3 and (3.55) it follows that

$$
\lim _{n \rightarrow \infty}\left\|x_{n}-w_{n}\right\|=0
$$

Since $J$ is uniformly norm-to-norm continuous, we also have

$$
\lim _{n \rightarrow \infty}\left\|J x_{n}-J w_{n}\right\|=0
$$

Again by the triangle inequality, we get

$$
\begin{aligned}
\left\|w_{n}-T_{n} v_{n}\right\| & =\left\|w_{n}-x_{n}+x_{n}-T_{n} v_{n}\right\| \\
& \leq\left\|w_{n}-x_{n}\right\|+\left\|x_{n}-T_{n} v_{n}\right\|
\end{aligned}
$$

From (3.50) and (3.57), we have

$$
\lim _{n \rightarrow \infty}\left\|w_{n}-T_{n} v_{n}\right\|=0
$$


From (3.5), we have $\phi\left(q, v_{n}\right) \geq\left(1 /\left(1-\beta_{n}\right)\right)\left(\phi\left(q, z_{n}\right)-\beta_{n} \phi\left(q, x_{n}\right)\right)$, it follows from Lemma 2.8 and (3.10), we note that

$$
\begin{aligned}
\phi\left(v_{n}, w_{n}\right) & =\phi\left(J_{r_{n}} w_{n}, w_{n}\right) \leq \phi\left(q, w_{n}\right)-\phi\left(q, J_{r_{n}} w_{n}\right) \\
& =\phi\left(q, w_{n}\right)-\phi\left(q, v_{n}\right) \\
& \leq \phi\left(q, w_{n}\right)-\frac{1}{1-\beta_{n}}\left(\phi\left(q, z_{n}\right)-\beta_{n} \phi\left(q, x_{n}\right)\right) \\
& \leq \phi\left(q, x_{n}\right)-\frac{1}{1-\beta_{n}}\left(\phi\left(q, z_{n}\right)-\beta_{n} \phi\left(q, x_{n}\right)\right) \\
& =\frac{1}{1-\beta_{n}}\left(\phi\left(q, x_{n}\right)-\phi\left(q, z_{n}\right)\right) \\
& =\frac{1}{1-\beta_{n}}\left(\left\|x_{n}\right\|^{2}-\left\|z_{n}\right\|^{2}-2\left\langle q, J x_{n}-J z_{n}\right\rangle\right) \\
& \leq \frac{1}{1-\beta_{n}}\left(\left\|x_{n}\right\|^{2}-\left\|z_{n}\right\|^{2}+2\left|\left\langle q, J x_{n}-J z_{n}\right\rangle\right|\right) \\
& \leq \frac{1}{1-\beta_{n}}\left(\left|\left\|x_{n}\right\|-\left\|z_{n}\right\|\right|\left(\left\|x_{n}\right\|+\left\|z_{n}\right\|\right)+2\|q\|\left\|J x_{n}-J z_{n}\right\|\right) \\
& \leq \frac{1}{1-\beta_{n}}\left(\left\|x_{n}-z_{n}\right\|\left(\left\|x_{n}\right\|+\left\|z_{n}\right\|\right)+2\|q\|\left\|J x_{n}-J z_{n}\right\|\right) .
\end{aligned}
$$

It follows from $\lim \inf _{n \rightarrow \infty}\left(1-\beta_{n}\right)>0,(3.30)$ and (3.31), we get

$$
\lim _{n \rightarrow \infty} \phi\left(v_{n}, w_{n}\right)=0
$$

From Lemma 2.3, it follows that

$$
\lim _{n \rightarrow \infty}\left\|v_{n}-w_{n}\right\|=0
$$

By using the triangle inequality, we get

$$
\begin{aligned}
\left\|v_{n}-T_{n} v_{n}\right\| & =\left\|v_{n}-w_{n}+w_{n}-T_{n} v_{n}\right\| \\
& \leq\left\|v_{n}-w_{n}\right\|+\left\|w_{n}-T_{n} v_{n}\right\| .
\end{aligned}
$$

From (3.60) and (3.63), we have

$$
\lim _{n \rightarrow \infty}\left\|v_{n}-T_{n} v_{n}\right\|=0
$$

Since $\left\|x_{n}-v_{n}\right\| \leq\left\|x_{n}-w_{n}\right\|+\left\|w_{n}-v_{n}\right\|$, (3.57) and (3.63), then

$$
\lim _{n \rightarrow \infty}\left\|x_{n}-v_{n}\right\|=0 .
$$


From (3.66) and since $x_{n} \rightarrow p$, then $v_{n} \rightarrow p$. By (3.60) it follows from (*)-condition, that $p \in \bigcap_{n=1}^{\infty} F\left(T_{n}\right)$. Hence $p \in\left(\bigcap_{n=1}^{\infty} F\left(S_{n}\right)\right) \cap\left(\bigcap_{n=1}^{\infty} F\left(T_{n}\right)\right)$.

(b) We show that $x_{n} \rightarrow p \in \operatorname{GMEP}(\theta, B, \varphi)$. Indeed, it follows from (A2), that

$$
\left\langle B u_{n}, y-u_{n}\right\rangle+\varphi(y)-\varphi\left(u_{n}\right)+\frac{1}{r_{n}}\left\langle y-u_{n}, J u_{n}-J y_{n}\right\rangle \geq-\theta\left(u_{n}, y\right) \geq \theta\left(y, u_{n}\right), \quad \forall y \in C,
$$

and hence

$$
\left\langle B u_{n}, y-u_{n}\right\rangle+\varphi(y)-\varphi\left(u_{n}\right)+\left\langle y-u_{n} \frac{\left(J u_{n}-J y_{n}\right)}{r_{n}}\right\rangle \geq \theta\left(y, u_{n}\right), \quad \forall y \in C
$$

For $t$ with $0<t \leq 1$ and $y \in C$, let $y_{t}=t y+(1-t) p$. Then, we get that $y_{t} \in C$. From (3.68), it follows that

$$
\begin{aligned}
\left\langle B y_{t}, y_{t}-u_{n}\right\rangle \geq & \left\langle B y_{t}, y_{t}-u_{n}\right\rangle-\left\langle B u_{n}, y_{t}-u_{n}\right\rangle-\varphi\left(y_{t}\right)+\varphi\left(u_{n}\right) \\
& -\left\langle y_{t}-u_{n}, \frac{\left(J u_{n}-J y_{n}\right)}{r_{n}}\right\rangle+\theta\left(y_{t}, u_{n}\right) \\
= & \left\langle B y_{t}-B u_{n}, y_{t}-u_{n}\right\rangle-\varphi\left(y_{t}\right)+\varphi\left(u_{n}\right) \\
& -\left\langle y_{t}-u_{n}, \frac{\left(J u_{n}-J y_{n}\right)}{r_{n}}\right\rangle+\theta\left(y_{t}, u_{n}\right), \quad \forall y_{t} \in C .
\end{aligned}
$$

By the fact that $y_{n}, u_{n} \rightarrow p$ as $n \rightarrow \infty$, and $\left\|J u_{n}-J y_{n}\right\| / r_{n} \rightarrow 0$ as $n \rightarrow \infty$. Since $B$ is monotone, we know that $\left\langle B y_{t}-B u_{n}, y_{t}-u_{n}\right\rangle \geq 0$. Thus, it follows from (A4) that

$$
\begin{aligned}
\theta\left(y_{t}, p\right)-\varphi\left(y_{t}\right)+\varphi(p) & \leq \liminf _{n \rightarrow \infty} \theta\left(y_{t}, u_{n}\right)-\varphi\left(y_{t}\right)+\varphi\left(u_{n}\right) \leq \lim _{n \rightarrow \infty}\left\langle B y_{t}, y_{t}-u_{n}\right\rangle \\
& =\left\langle B y_{t}, y_{t}-p\right\rangle
\end{aligned}
$$

By the conditions (A1), (A4) and convexity of $\varphi$, we have

$$
\begin{aligned}
0 & =\theta\left(y_{t}, y_{t}\right)+\varphi\left(y_{t}\right)-\varphi\left(y_{t}\right) \\
& \leq t \theta\left(y_{t}, y\right)+(1-t) \theta\left(y_{t}, p\right)+t \varphi(y)+(1-t) \varphi(p)-\varphi\left(y_{t}\right) \\
& =t\left[\theta\left(y_{t}, y\right)+\varphi(y)-\varphi\left(y_{t}\right)\right]+(1-t)\left[\theta\left(y_{t}, p\right)+\varphi(p)-\varphi\left(y_{t}\right)\right] \\
& \leq t\left[\theta\left(y_{t}, y\right)+\varphi(y)-\varphi\left(y_{t}\right)\right]+(1-t)\left[\left\langle B y_{t}, y_{t}-p\right\rangle\right] \\
& =t\left[\theta\left(y_{t}, y\right)+\varphi(y)-\varphi\left(y_{t}\right)\right]+(1-t) t\left[\left\langle B y_{t}, y-p\right\rangle\right]
\end{aligned}
$$


and hence

$$
0 \leq \theta\left(y_{t}, y\right)+\varphi(y)-\varphi\left(y_{t}\right)+(1-t)\left\langle B y_{t}, y-p\right\rangle
$$

From (A3) and the weakly lower semicontinuity of $\varphi$, letting $t \rightarrow 0$, we also have

$$
\theta(p, y)+\langle B p, y-p\rangle+\varphi(y)-\varphi(p) \geq 0, \quad \forall y \in C
$$

This implies that $p \in \operatorname{GMEP}\left({ }^{\prime}, \mathrm{B},{ }^{\prime}\right)$.

(c) We show that $x_{n} \rightarrow p \in \operatorname{VI}(A, C)$. Indeed, define a set-valued $U: E \rightrightarrows E^{*}$ by Lemma 2.9, $U$ is maximal monotone and $U^{-1} 0=\operatorname{VI}(A, C)$. Let $(v, w) \in G(U)$. Since $w \in U v=A v+N_{C}(v)$, we get $w-A v \in N_{C}(v)$.

From $w_{n} \in C$, we have

$$
\left\langle v-w_{n}, w-A v\right\rangle \geq 0
$$

On the other hand, since $w_{n}=\Pi_{C} J^{-1}\left(J x_{n}-\lambda_{n} A x_{n}\right)$. Then by Lemma 2.4, we have

$$
\left\langle v-w_{n}, J w_{n}-\left(J x_{n}-\lambda_{n} A x_{n}\right)\right\rangle \geq 0,
$$

and thus

$$
\left\langle v-w_{n}, \frac{J x_{n}-J w_{n}}{\lambda_{n}}-A x_{n}\right\rangle \leq 0
$$

It follows from (3.74) and (3.76), that

$$
\begin{aligned}
\left\langle v-w_{n}, w\right\rangle & \geq\left\langle v-w_{n}, A v\right\rangle \\
& \geq\left\langle v-w_{n}, A v\right\rangle+\left\langle v-w_{n}, \frac{J x_{n}-J w_{n}}{\lambda_{n}}-A x_{n}\right\rangle \\
& =\left\langle v-w_{n}, A v-A x_{n}\right\rangle+\left\langle v-w_{n}, \frac{J x_{n}-J w_{n}}{\lambda_{n}}\right\rangle \\
& =\left\langle v-w_{n}, A v-A w_{n}\right\rangle+\left\langle v-w_{n}, A w_{n}-A x_{n}\right\rangle+\left\langle v-w_{n}, \frac{J x_{n}-J w_{n}}{\lambda_{n}}\right\rangle \\
& \geq-\left\|v-w_{n}\right\| \frac{\left\|w_{n}-x_{n}\right\|}{\alpha}-\left\|v-w_{n}\right\| \frac{\left\|J x_{n}-J w_{n}\right\|}{a} \\
& \geq-M\left(\frac{\left\|w_{n}-x_{n}\right\|}{\alpha}+\frac{\left\|J x_{n}-J w_{n}\right\|}{a}\right),
\end{aligned}
$$

where $M=\sup _{n \geq 1}\left\|v-w_{n}\right\|$. Take the limit as $n \rightarrow \infty$, (3.57) and (3.58), we obtain $\langle v-p, w\rangle \geq$ 0 . By the maximality of $U$, we have $p \in U^{-1} 0$ and hence $p \in \operatorname{VI}(A, C)$. 
(d) We show that $x_{n} \rightarrow p \in T^{-1} 0$. Since $J$ is uniformly norm-to-norm continuous on bounded sets, from (3.63), we get

$$
\lim _{n \rightarrow \infty}\left\|J w_{n}-J v_{n}\right\|=0
$$

From $r_{n} \geq d$, we have

$$
\lim _{n \rightarrow \infty} \frac{1}{r_{n}}\left\|J w_{n}-J v_{n}\right\|=0
$$

Since $J_{r_{n}} w_{n}=v_{n}$, therefore,

$$
\lim _{n \rightarrow \infty}\left\|T_{r_{n}} w_{n}\right\|=\lim _{n \rightarrow \infty} \frac{1}{r_{n}}\left\|J w_{n}-J J_{r_{n}} w_{n}\right\|=\lim _{n \rightarrow \infty} \frac{1}{r_{n}}\left\|J w_{n}-J v_{n}\right\|=0
$$

For $\left(w, w^{*}\right) \in G(T)$, from the monotonicity of $T$, we have $\left\langle w-v_{n}, w^{*}-T_{r_{n}} w_{n}\right\rangle \geq 0$ for all $n \geq 0$. Letting $n \rightarrow \infty$, we get $\left\langle w-p, w^{*}\right\rangle \geq 0$. From the maximality of $T$, we have $p \in T^{-1} 0$. Hence, from (a), (b), (c) and (d), we obtain $p \in \Theta$.

Step 7. we show that $p=\Pi_{\Theta} x_{0}$. have

From $x_{n}=\Pi_{C_{n}} x_{0}$, we have $\left\langle J x_{0}-J x_{n}, x_{n}-z\right\rangle \geq 0$, for all $z \in C_{n}$. Since $\Theta \subset C_{n}$, we also

$$
\left\langle J x_{0}-J x_{n}, x_{n}-y\right\rangle \geq 0, \quad \forall y \in \Theta
$$

Taking limit $n \rightarrow \infty$, we obtain

$$
\left\langle J x_{0}-J p, p-y\right\rangle \geq 0, \quad \forall y \in \Theta .
$$

By Lemma 2.4, we can conclude that $p=\Pi_{\Theta} x_{0}$ and $x_{n} \rightarrow p$ as $n \rightarrow \infty$. This completes the proof.

Theorem 3.2. Let $C$ be a nonempty closed and convex subset of a 2-uniformly convex and uniformly smooth Banach space $E$. Let $T: E \rightrightarrows E^{*}$ be a maximal monotone operator satisfying $D(T) \subset C$ and let $J_{r}=(J+r T)^{-1} J$ for all $r>0$, where $J$ is the duality mapping on E. Let $\theta$ be a bifunction from $C \times C$ to $\mathbb{R}$ satisfying $(A 1)-(A 4)$, and let $\varphi: C \rightarrow \mathbb{R}$ be a proper lower semicontinuous and convex function. Let $A$ be an $\alpha$-inverse-strongly monotone mapping of $C$ into $E^{*}$ satisfy $\|A y\| \leq\|A y-A u\|$, for all $y \in C$ and $u \in V I(A, C) \neq \emptyset$ and let $B: C \rightarrow E^{*}$ be a continuous and monotone mapping. Let $S_{n}, T_{n}: C \rightarrow C$ be two families of relatively quasi-nonexpansive mappings with satisfy the NST-condition such that $\Theta:=\left(\bigcap_{n=1}^{\infty} F\left(S_{n}\right)\right) \cap\left(\bigcap_{n=1}^{\infty} F\left(T_{n}\right)\right) \cap T^{-1} 0 \cap \operatorname{GMEP}\left({ }^{\prime}, \mathrm{B},{ }^{\prime}\right) \cap V I(\mathrm{~A}, \mathrm{C}) \neq \emptyset$. For an initial point $x_{0} \in E$ with $x_{1}=\Pi_{C_{1}} x_{0}$ and $C_{1}=C$, we define the sequence $\left\{x_{n}\right\}$ by (3.2) where $\left\{\alpha_{n}\right\},\left\{\beta_{n}\right\}$ are sequences in $[0,1]$ and $\left\{r_{n}\right\} \subset[d, \infty)$ for some $d>0$ and $\left\{\lambda_{n}\right\} \subset[a, b]$ for some $a, b$ with $0<a<b<c^{2} \alpha / 2$, where $1 / c$ is the 2-uniformly convexity constant of $E$. If $\lim _{\inf _{n \rightarrow \infty}}\left(1-\alpha_{n}\right)>0$ and $\lim _{\inf _{n \rightarrow \infty}}\left(1-\beta_{n}\right)>0$, then $\left\{x_{n}\right\}$ converges strongly to $p \in \Theta$, where $p=\Pi_{\Theta} x_{0}$. 
Proof. If $\left\{T_{n}\right\},\left\{S_{n}\right\}$ satisfy NST-condition, then $\left\{T_{n}\right\},\left\{S_{n}\right\}$ satisfy $(*)$-condition.

Setting $S_{n} \equiv S$ and $T_{n} \equiv T$ in Theorem 3.1, then we obtain the following result.

Corollary 3.3. Let $C$ be a nonempty closed and convex subset of a 2-uniformly convex and uniformly smooth Banach space E. Let $\widetilde{T}: E \rightrightarrows E^{*}$ be a maximal monotone operator satisfying $D(\widetilde{T}) \subset C$ and let $J_{r}=(J+r \widetilde{T})^{-1} J$ for all $r>0$. Let $\theta$ be a bifunction from $C \times C$ to $\mathbb{R}$ satisfying $(A 1)-(A 4)$, and let $\varphi: C \rightarrow \mathbb{R}$ be a proper lower semicontinuous and convex function. Let $A$ be an $\alpha$-inverse-strongly monotone mapping of $C$ into $E^{*}$ satisfying $\|A y\| \leq\|A y-A u\|$, for all $y \in C$ and $u \in V I(A, C) \neq \emptyset$ and let $B: C \rightarrow E^{*}$ be a continuous and monotone mapping. Let $T, S: C \rightarrow C$ be two closed relatively quasi-nonexpansive mappings such that $\Theta:=F(S) \cap F(T) \cap \widetilde{T}^{-1} 0 \cap \operatorname{GMEP}\left({ }^{\prime}, \mathrm{B}^{\prime}{ }^{\prime}\right) \cap \operatorname{VI}(\mathrm{A}, \mathrm{C}) \neq \emptyset$. For an initial point $x_{0} \in E$ with $x_{1}=\Pi_{C_{1}} x_{0}$ and $C_{1}=C$, we define the sequence $\left\{x_{n}\right\}$ as follows:

$$
\begin{gathered}
w_{n}=\Pi_{C} J^{-1}\left(J x_{n}-\lambda_{n} A x_{n}\right), \\
z_{n}=J^{-1}\left(\beta_{n} J x_{n}+\left(1-\beta_{n}\right) J T J_{r_{n}} w_{n}\right), \\
y_{n}=J^{-1}\left(\alpha_{n} J x_{n}+\left(1-\alpha_{n}\right) J S z_{n}\right), \\
u_{n} \in C \text { such that } \theta\left(u_{n}, y\right)+\varphi(y)-\varphi\left(u_{n}\right)+\left\langle B u_{n}, y-u_{n}\right\rangle+\frac{1}{r_{n}}\left\langle y-u_{n}, J u_{n}-J y_{n}\right\rangle \\
\geq 0, \quad \forall y \in C, \\
C_{n+1}=\left\{z \in C_{n}: \phi\left(z, u_{n}\right) \leq \phi\left(z, z_{n}\right) \leq \phi\left(z, x_{n}\right)\right\}, \\
x_{n+1}=\prod_{C_{n+1}} x_{0}, \quad \forall n \geq 1,
\end{gathered}
$$

where $J$ is the duality mapping on $E,\left\{\alpha_{n}\right\},\left\{\beta_{n}\right\}$ are sequences in $[0,1]$ and $\left\{r_{n}\right\} \subset[d, \infty)$ for some $d>0$ and $\left\{\lambda_{n}\right\} \subset[a, b]$ for some $a, b$ with $0<a<b<c^{2} \alpha / 2$, where $1 / c$ is the 2-uniformly convexity constant of $E$. If $\lim \inf _{n \rightarrow \infty}\left(1-\alpha_{n}\right)>0$ and $\lim _{\inf _{n \rightarrow \infty}}\left(1-\beta_{n}\right)>0$, then $\left\{x_{n}\right\}$ converges strongly to $p \in \Theta$, where $p=\Pi_{\Theta} x_{0}$.

Next, we consider the problem of finding a zero point of an inverse-strongly monotone operator of $E$ into $E^{*}$. Assume that $A$ satisfies the conditions:

(C1) $A$ is $\alpha$-inverse-strongly monotone,

(C2) $A^{-1} 0=\{u \in E: A u=0\} \neq \emptyset$.

Hence, setting $\widetilde{T} x \equiv 0$, for all $x \in C$ in Corollary 3.3, then $J_{r}=I$, we also have the following result.

Corollary 3.4. Let $E$ be a 2-uniformly convex and uniformly smooth Banach space. Let $\theta$ be a bifunction from $E \times E$ to $\mathbb{R}$ satisfying (A1)-(A4), and let $\varphi: E \rightarrow \mathbb{R}$ be a proper lower semicontinuous and convex function. Let $A$ be an operator of $E$ into $E^{*}$ satisfying $(C 1)$ and (C2), and let $B: E \rightarrow E^{*}$ be a continuous and monotone mapping. Let $T, S: E \rightarrow E$ be two closed relatively quasi-nonexpansive mappings such that

$$
\Theta:=F(S) \cap F(T) \cap \operatorname{GMEP}\left({ }^{\prime}, \mathrm{B}^{\prime}{ }^{\prime}\right) \cap \mathrm{A}^{-1} 0 \neq \emptyset .
$$


For an initial point $x_{0} \in E$ with $x_{1}=\Pi_{E_{1}} x_{0}$ and $E_{1}=E$, we define the sequence $\left\{x_{n}\right\}$ as follows:

$$
\begin{gathered}
w_{n}=\Pi_{C} J^{-1}\left(J x_{n}-\lambda_{n} A x_{n}\right), \\
z_{n}=J^{-1}\left(\beta_{n} J x_{n}+\left(1-\beta_{n}\right) J T w_{n}\right), \\
y_{n}=J^{-1}\left(\alpha_{n} J x_{n}+\left(1-\alpha_{n}\right) J S z_{n}\right),
\end{gathered}
$$

$u_{n} \in C$ such that $\theta\left(u_{n}, y\right)+\varphi(y)-\varphi\left(u_{n}\right)+\left\langle B u_{n}, y-u_{n}\right\rangle+\frac{1}{r_{n}}\left\langle y-u_{n}, J u_{n}-J y_{n}\right\rangle \geq 0, \quad \forall y \in E$,

$$
\begin{gathered}
E_{n+1}=\left\{z \in E_{n}: \phi\left(z, u_{n}\right) \leq \phi\left(z, z_{n}\right) \leq \phi\left(z, x_{n}\right)\right\}, \\
x_{n+1}=\prod_{E_{n+1}} x_{0}, \quad \forall n \geq 1,
\end{gathered}
$$

where $J$ is the duality mapping on $E,\left\{\alpha_{n}\right\},\left\{\beta_{n}\right\}$ are sequences in $[0,1]$ and $\left\{r_{n}\right\} \subset[d, \infty)$ for some $d>0$ and $\left\{\lambda_{n}\right\} \subset[a, b]$ for some $a, b$ with $0<a<b<c^{2} \alpha / 2$, where $1 / c$ is the 2-uniformly convexity constant of $E$. If $\lim \inf _{n \rightarrow \infty}\left(1-\alpha_{n}\right)>0$ and $\lim _{\inf _{n \rightarrow \infty}}\left(1-\beta_{n}\right)>0$, then $\left\{x_{n}\right\}$ converges strongly to $p \in \Theta$, where $p=\Pi_{\Theta} x_{0}$.

Proof. Setting $\widetilde{T} x \equiv 0$, for all $x \in C$, then, $D(\widetilde{T})=E$ and hence $C=E$ in Corollary 3.3, we also get $\Pi_{E}=I$. We also have $\operatorname{VI}(A, C)=\operatorname{VI}(A, E)=\{x \in E: A x=0\} \neq \emptyset$ and then the condition $\|A y\| \leq\|A y-A u\|$ holds for all $y \in E$ and $u \in A^{-1} 0$. So, we obtain the result. Corollary.

Setting $A \equiv 0$ in Corollary 3.4, then we get $w_{n}=x_{n}$. Hence we obtain the following

Corollary 3.5. Let $C$ be a nonempty closed and convex subset of a 2-uniformly convex and uniformly smooth Banach space $E$. Let $\theta$ be a bifunction from $C \times C$ to $\mathbb{R}$ satisfying (A1)-(A4), and let $\varphi: C \rightarrow \mathbb{R}$ be a proper lower semicontinuous and convex function. Let $B: C \rightarrow E^{*}$ be a continuous and monotone mapping. Let $T, S: C \rightarrow C$ be two closed relatively quasi-nonexpansive mappings such that

$$
\Theta:=F(S) \cap F(T) \cap \operatorname{GMEP}\left({ }^{\prime}, \mathrm{B},{ }^{\prime}\right) \neq \emptyset .
$$

For an initial point $x_{0} \in E$ with $x_{1}=\Pi_{C_{1}} x_{0}$ and $C_{1}=C$, we define the sequence $\left\{x_{n}\right\}$ as follows:

$$
\begin{gathered}
z_{n}=J^{-1}\left(\beta_{n} J x_{n}+\left(1-\beta_{n}\right) J T x_{n}\right), \\
y_{n}=J^{-1}\left(\alpha_{n} J x_{n}+\left(1-\alpha_{n}\right) J S z_{n}\right), \\
u_{n} \in C \text { such that } \theta\left(u_{n}, y\right)+\varphi(y)-\varphi\left(u_{n}\right)+\left\langle B u_{n}, y-u_{n}\right\rangle+\frac{1}{r_{n}}\left\langle y-u_{n}, J u_{n}-J y_{n}\right\rangle \geq 0, \quad \forall y \in C, \\
C_{n+1}=\left\{z \in C_{n}: \phi\left(z, u_{n}\right) \leq \phi\left(z, z_{n}\right) \leq \phi\left(z, x_{n}\right)\right\}, \\
x_{n+1}=\prod_{C_{n+1}} x_{0}, \quad \forall n \geq 1,
\end{gathered}
$$


where $J$ is the duality mapping on $E,\left\{\alpha_{n}\right\},\left\{\beta_{n}\right\}$ are sequences in $[0,1]$ and $\left\{r_{n}\right\} \subset[d, \infty)$ for some $d>0$ and $\left\{\lambda_{n}\right\} \subset[a, b]$ for some $a, b$ with $0<a<b<c^{2} \alpha / 2$, where $1 / c$ is the 2-uniformly convexity constant of $E$. If $\lim \inf _{n \rightarrow \infty}\left(1-\alpha_{n}\right)>0$ and $\lim _{\inf _{n \rightarrow \infty}}\left(1-\beta_{n}\right)>0$, then $\left\{x_{n}\right\}$ converges strongly to $p \in \Theta$, where $p=\Pi_{\Theta} x_{0}$.

Remark 3.6. Theorem 3.1, Corollaries 3.4 and 3.5 improve and extend the corresponding results in Cholamjiak [36], Wei et al. [37] and Saewan et al. [26].

\section{Application to Complementarity Problem}

Let $K$ be a nonempty, closed convex cone in $E$. We define the polar $K^{*}$ of $K$ as follows:

$$
K^{*}=\left\{y^{*} \in E^{*}:\left\langle x, y^{*}\right\rangle \geq 0, \forall x \in K\right\}
$$

If $A: K \rightarrow E^{*}$ is an operator, then an element $u \in K$ is called a solution of the complementarity problem $([31])$ if

$$
A u \in K^{*}, \quad\langle u, A u\rangle=0 .
$$

The set of solutions of the complementarity problem is denoted by $C(A, K)$.

Theorem 4.1. Let $K$ be a nonempty and closed convex subset of a 2-uniformly convex and uniformly smooth Banach space E. Let $\widetilde{A}: E \rightrightarrows E^{*}$ be a maximal monotone operator satisfying $D(\widetilde{A}) \subset K$ and let $J_{r}=(J+r \widetilde{A})^{-1} J$ for all $r>0$. Let $\theta$ be a bifunction from $K \times K$ to $\mathbb{R}$ satisfying (A1)-(A4), and let $\varphi: K \rightarrow \mathbb{R}$ be a proper lower semicontinuous and convex function. Let $A: K \rightarrow E^{*}$ be an $\alpha$-inverse-strongly monotone mapping of $E$ into $E^{*}$ satisfying $\|A y\| \leq\|A y-A u\|$, for all $y \in K$ and $u \in C(A, K) \neq \emptyset$ and let $B: K \rightarrow E^{*}$ be a continuous and monotone mapping. Let $S, T: K \rightarrow K$ be two closed relatively quasi-nonexpansive mappings such that $\Theta:=F(S) \cap F(T) \cap$ $\widetilde{A}^{-1} 0 \cap \operatorname{GMEP}\left({ }^{\prime}, \mathrm{B},{ }^{\prime}\right) \cap \mathrm{C}(\mathrm{A}, \mathrm{K}) \neq \emptyset$. For an initial point $x_{0} \in E$ with $x_{1}=\Pi_{K_{1}} x_{0}$ and $K_{1}=K$, we define the sequence $\left\{x_{n}\right\}$ as follows:

$$
\begin{gathered}
w_{n}=\Pi_{K} J^{-1}\left(J x_{n}-\lambda_{n} A x_{n}\right), \\
z_{n}=J^{-1}\left(\beta_{n} J x_{n}+\left(1-\beta_{n}\right) J T J_{r_{n}} w_{n}\right), \\
y_{n}=J^{-1}\left(\alpha_{n} J x_{n}+\left(1-\alpha_{n}\right) J S z_{n}\right), \\
u_{n} \in K \text { such that } \theta\left(u_{n}, y\right)+\varphi(y)-\varphi\left(u_{n}\right)+\left\langle B u_{n}, y-u_{n}\right\rangle+\frac{1}{r_{n}}\left\langle y-u_{n}, J u_{n}-J y_{n}\right\rangle \geq 0, \quad \forall y \in K, \\
K_{n+1}=\left\{z \in K_{n}: \phi\left(z, u_{n}\right) \leq \phi\left(z, z_{n}\right) \leq \phi\left(z, x_{n}\right)\right\}, \\
x_{n+1}=\prod_{K_{n+1}} x_{0}, \quad \forall n \geq 1,
\end{gathered}
$$

where $J$ is the duality mapping on $E,\left\{\alpha_{n}\right\}$ and $\left\{\beta_{n}\right\}$ are sequences in $[0,1]$ and $\left\{r_{n}\right\} \subset[d, \infty)$ for some $d>0$ and $\left\{\lambda_{n}\right\} \subset[a, b]$ for some $a, b$ with $0<a<b<c^{2} \alpha / 2$, where $1 / c$ is the 2-uniformly 
convexity constant of $E$. If $\lim \inf _{n \rightarrow \infty}\left(1-\alpha_{n}\right)>0$ and $\lim _{\inf _{n \rightarrow \infty}}\left(1-\beta_{n}\right)>0$, then $\left\{x_{n}\right\}$ converges strongly to $p \in \Theta$, where $p=\Pi_{\Theta} x_{0}$.

Proof. As in the proof of Takahashi in [31, Lemma 7.11], we get that $\operatorname{VI}(A, K)=C(A, K)$. So, we obtain the result.

\section{Acknowledgments}

The authors are grateful for Professor Douglas Robert Anderson and the reviewers for the careful reading of the paper and for the suggestions which improved the quality of this work. This paper was financially supported by grant from under the program Strategic Scholarships for Frontier Research Network for the Join Ph.D. Program Thai Doctoral degree from the Office of the Higher Education Commission, Thailand and the King Mongkut's Dimond scholarship for Ph.D. program at King Mongkut's University of Technology Thonburi (NRU KMUTT, under CSEC project) during its preparation. The second author was supported by the Higher Education Commission and the Thailand Research Fund under Grant MRG5380044.

\section{References}

[1] E. Blum and W. Oettli, "From optimization and variational inequalities to equilibrium problems," The Mathematics Student, vol. 63, no. 1-4, pp. 123-145, 1994.

[2] C. Klin-eam, S. Suantai, and W. Takahashi, "Strong convergence of generalized projection algorithms for nonlinear operators," Abstract and Applied Analysis, vol. 2009, Article ID 649831, 18 pages, 2009.

[3] W. Cholamjiak and S. Suantai, "A hybrid method for a countable family of multivalued maps, equilibrium problems, and variational inequality problems," Discrete Dynamics in Nature and Society, vol. 2010, Article ID 349158, 14 pages, 2010.

[4] P. L. Combettes and S. A. Hirstoaga, "Equilibrium programming in Hilbert spaces," Journal of Nonlinear and Convex Analysis, vol. 6, no. 1, pp. 117-136, 2005.

[5] C. Jaiboon and P. Kumam, "A general iterative method for solving equilibrium problems, variational inequality problems and fixed point problems of an infinite family of nonexpansive mappings," Journal of Applied Mathematics and Computing, vol. 34, no. 1-2, pp. 407-439, 2010.

[6] P. Katchang and P. Kumam, "A new iterative algorithm of solution for equilibrium problems, variational inequalities and fixed point problems in a Hilbert space," Journal of Applied Mathematics and Computing, vol. 32, no. 1, pp. 19-38, 2010.

[7] P. Kumam, "A new hybrid iterative method for solution of equilibrium problems and fixed point problems for an inverse strongly monotone operator and a nonexpansive mapping," Journal of Applied Mathematics and Computing, vol. 29, no. 1-2, pp. 263-280, 2009.

[8] A. Moudafi, "Second-order differential proximal methods for equilibrium problems," Journal of Inequalities in Pure and Applied Mathematics, vol. 4, no. 1, article 18, 2003.

[9] X. Qin, Y. J. Cho, and S. M. Kang, "Convergence theorems of common elements for equilibrium problems and fixed point problems in Banach spaces," Journal of Computational and Applied Mathematics, vol. 225, no. 1, pp. 20-30, 2009.

[10] X. Qin, S. Y. Cho, and S. M. Kang, "Strong convergence of shrinking projection methods for quasi- $\varphi$ nonexpansive mappings and equilibrium problems," Journal of Computational and Applied Mathematics, vol. 234, no. 3, pp. 750-760, 2010.

[11] S. Saewan and P. Kumam, "Modified hybrid block iterative algorithm for convex feasibility problems and generalized equilibrium problems for uniformly quasi- $\varphi$-asymptotically nonexpansive mappings," Abstract and Applied Analysis, vol. 2010, Article ID 357120, 22 pages, 2010.

[12] K. Ball, E. A. Carlen, and E. H. Lieb, "Sharp uniform convexity and smoothness inequalities for trace norms," Inventiones Mathematicae, vol. 115, no. 3, pp. 463-482, 1994.

[13] Y. Takahashi, K. Hashimoto, and M. Kato, "On sharp uniform convexity, smoothness, and strong type, cotype inequalities," Journal of Nonlinear and Convex Analysis, vol. 3, no. 2, pp. 267-281, 2002. 
[14] R. T. Rockafellar, "On the maximality of sums of nonlinear monotone operators," Transactions of the American Mathematical Society, vol. 149, pp. 75-88, 1970.

[15] R. T. Rockafellar, "Monotone operators and the proximal point algorithm," SIAM Journal on Control and Optimization, vol. 14, no. 5, pp. 877-898, 1976.

[16] Y. Su, M. Shang, and X. Qin, "A general iterative scheme for nonexpansive mappings and inversestrongly monotone mappings," Journal of Applied Mathematics and Computing, vol. 28, no. 1-2, pp. 283294, 2008.

[17] H. Zhou and X. Gao, "An iterative method of fixed points for closed and quasi-strict pseudocontractions in Banach spaces," Journal of Applied Mathematics and Computing, vol. 33, no. 1-2, pp. 227-237, 2010.

[18] S. Reich, "A weak convergence theorem for the alternating method with Bregman distances," in Theory and Applications of Nonlinear Operators of Accretive and Monotone type, A. G. Kartsatos, Ed., vol. 178 of Lecture Notes in Pure and Appl. Math., pp. 313-318, Marcel Dekker, New York, NY, USA, 1996.

[19] W. Nilsrakoo and S. Saejung, "Strong convergence to common fixed points of countable relatively quasi-nonexpansive mappings," Fixed Point Theory and Applications, vol. 2008, Article ID 312454, 19 pages, 2008.

[20] Y. Su, D. Wang, and M. Shang, "Strong convergence of monotone hybrid algorithm for hemi-relatively nonexpansive mappings," Fixed Point Theory and Applications, vol. 2008, Article ID 284613, 8 pages, 2008.

[21] H. Zegeye and N. Shahzad, "Strong convergence theorems for monotone mappings and relatively weak nonexpansive mappings," Nonlinear Analysis: Theory, Methods \& Applications, vol. 70, no. 7, pp. 2707-2716, 2009.

[22] D. Butnariu, S. Reich, and A. J. Zaslavski, "Asymptotic behavior of relatively nonexpansive operators in Banach spaces," Journal of Applied Analysis, vol. 7, no. 2, pp. 151-174, 2001.

[23] D. Butnariu, S. Reich, and A. J. Zaslavski, "Weak convergence of orbits of nonlinear operators in reflexive Banach spaces," Numerical Functional Analysis and Optimization, vol. 24, no. 5-6, pp. 489-508, 2003.

[24] Y. Censor and S. Reich, "Iterations of paracontractions and firmly nonexpansive operators with applications to feasibility and optimization," Optimization, vol. 37, no. 4, pp. 323-339, 1996.

[25] S.-y. Matsushita and W. Takahashi, "A strong convergence theorem for relatively nonexpansive mappings in a Banach space," Journal of Approximation Theory, vol. 134, no. 2, pp. 257-266, 2005.

[26] S. Saewan, P. Kumam, and K. Wattanawitoon, "Convergence theorem based on a new hybrid projection method for finding a common solution of generalized equilibrium and variational inequality problems in Banach spaces," Abstract and Applied Analysis, vol. 2010, Article ID 734126, 25 pages, 2010.

[27] Y. I. Alber, "Metric and generalized projection operators in Banach spaces: properties and applications," in Theory and Applications of Nonlinear Operators of Accretive and Monotone Type, A. G. Kartsatos, Ed., vol. 178 of Lecture Notes in Pure and Appl. Math., pp. 15-50, Marcel Dekker, New York, NY, USA, 1996.

[28] Y. I. Alber and S. Reich, "An iterative method for solving a class of nonlinear operator equations in Banach spaces," Panamerican Mathematical Journal, vol. 4, no. 2, pp. 39-54, 1994.

[29] I. Cioranescu, Geometry of Banach Spaces, Duality Mappings and Nonlinear Problems, vol. 62 of Mathematics and Its Applications, Kluwer Academic Publishers, Dordrecht, The Nethrlands, 1990.

[30] S. Kamimura and W. Takahashi, "Strong convergence of a proximal-type algorithm in a Banach space," SIAM Journal on Optimization, vol. 13, no. 3, pp. 938-945, 2002.

[31] W. Takahashi, Nonlinear Functional Analysis: Fixed Point Theory and Its Application, Yokohama Publishers, Yokohama, Japan, 2000.

[32] S.-y. Matsushita and W. Takahashi, "Weak and strong convergence theorems for relatively nonexpansive mappings in Banach spaces," Fixed Point Theory and Applications, no. 1, pp. 37-47, 2004.

[33] H. Iiduka and W. Takahashi, "Weak convergence of a projection algorithm for variational inequalities in a Banach space," Journal of Mathematical Analysis and Applications, vol. 339, no. 1, pp. 668-679, 2008.

[34] W. Takahashi and K. Zembayashi, "Strong and weak convergence theorems for equilibrium problems and relatively nonexpansive mappings in Banach spaces," Nonlinear Analysis: Theory, Methods $\mathcal{E}$ Applications, vol. 70, no. 1, pp. 45-57, 2009.

[35] W. Takahashi and K. Zembayashi, "Strong convergence theorem by a new hybrid method for equilibrium problems and relatively nonexpansive mappings," Fixed Point Theory and Applications, vol. 2008, Article ID 528476, 11 pages, 2008. 
[36] P. Cholamjiak, "A hybrid iterative scheme for equilibrium problems, variational inequality problems, and fixed point problems in Banach spaces," Fixed Point Theory and Applications, vol. 2009, Article ID 719360, 18 pages, 2009.

[37] L. Wei, Y. J. Cho, and H. Zhou, "A strong convergence theorem for common fixed points of two relatively nonexpansive mappings and its applications," Journal of Applied Mathematics and Computing, vol. 29, no. 1-2, pp. 95-103, 2009.

[38] G. Inoue, W. Takahashi, and K. Zembayashi, "Strong convergence theorems by hybrid methods for maximal monotone operators and relatively nonexpansive mappings in Banach spaces," Journal of Convex Analysis, vol. 16, no. 3-4, pp. 791-806, 2009.

[39] K. Nakajo, K. Shimoji, and W. Takahashi, "Strong convergence theorems by the hybrid method for families of nonexpansive mappings in Hilbert spaces," Taiwanese Journal of Mathematics, vol. 10, no. 2, pp. 339-360, 2006.

[40] Y. Kimura, K. Nakajo, and W. Takahashi, "Strongly convergent iterative schemes for a sequence of nonlinear mappings," Journal of Nonlinear and Convex Analysis, vol. 9, no. 3, pp. 407-416, 2008.

[41] H. K. Xu, "Inequalities in Banach spaces with applications," Nonlinear Analysis: Theory, Methods $\mathcal{E}$ Applications, vol. 16, no. 12, pp. 1127-1138, 1991.

[42] C. Chidume, Geometric Properties of Banach Spaces and Nonlinear Iterations, vol. 1965 of Lecture Notes in Mathematics, Springer, London, UK, 2009.

[43] F. Kohsaka and W. Takahashi, "Strong convergence of an iterative sequence for maximal monotone operators in a Banach space," Abstract and Applied Analysis, no. 3, pp. 239-249, 2004.

[44] F. Kohsaka and W. Takahashi, "Existence and approximation of fixed points of firmly nonexpansivetype mappings in Banach spaces," SIAM Journal on Optimization, vol. 19, no. 2, pp. 824-835, 2008.

[45] S.-s. Zhang, "Generalized mixed equilibrium problem in Banach spaces," Applied Mathematics and Mechanics. English Edition, vol. 30, no. 9, pp. 1105-1112, 2009. 


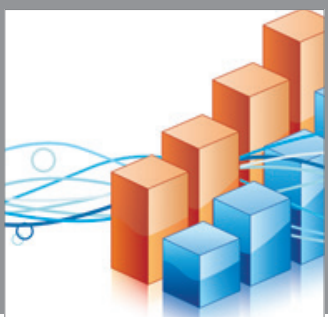

Advances in

Operations Research

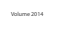

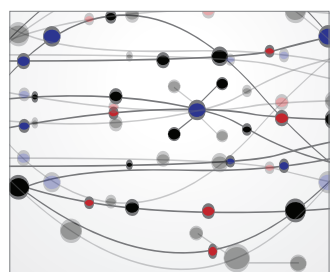

\section{The Scientific} World Journal
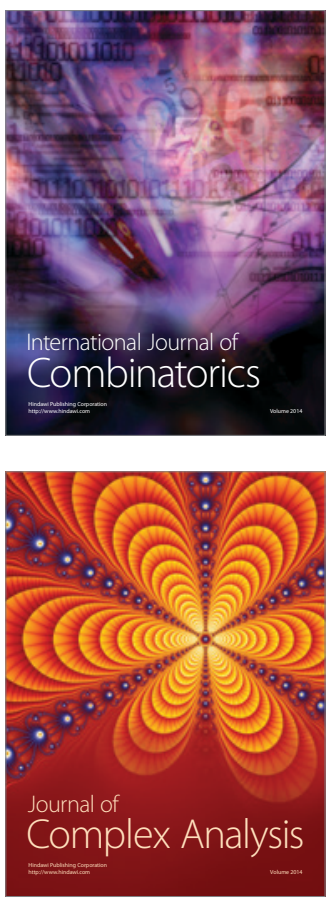

International Journal of

Mathematics and

Mathematical

Sciences
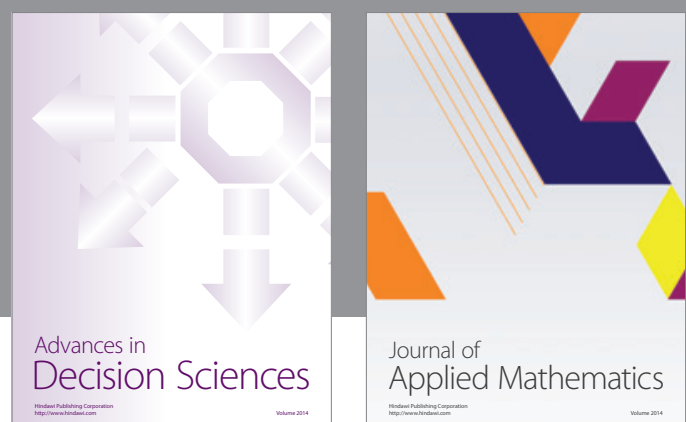

Journal of

Applied Mathematics
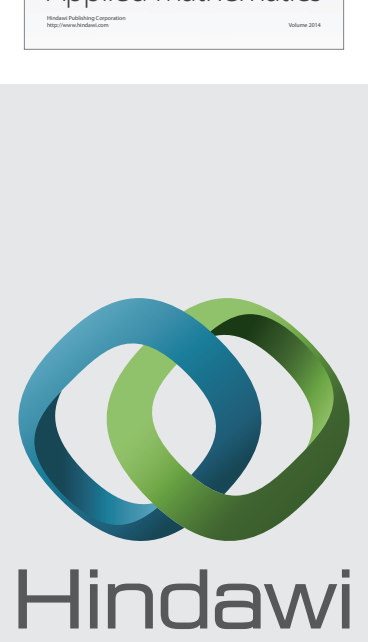

Submit your manuscripts at http://www.hindawi.com
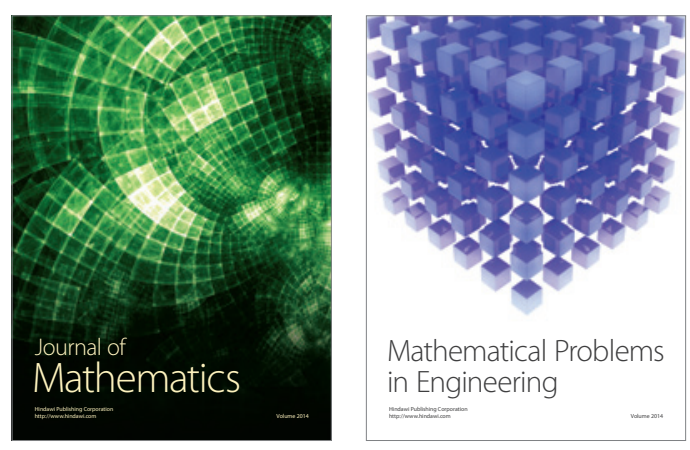

Mathematical Problems in Engineering
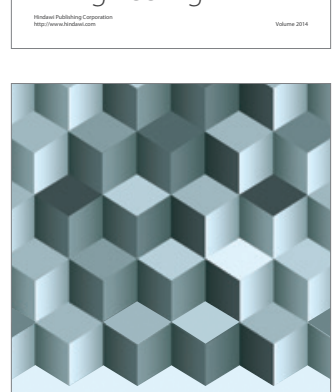

Journal of

Function Spaces
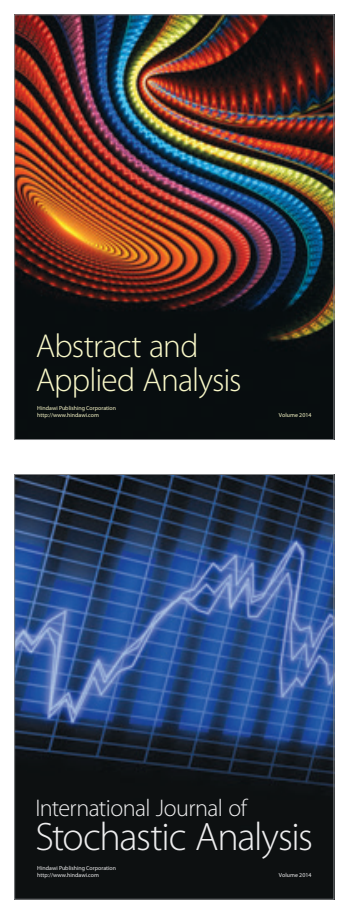

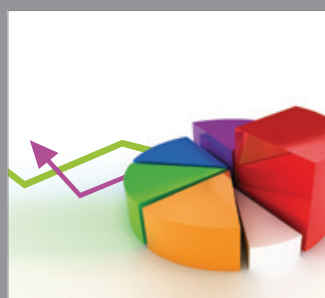

ournal of

Probability and Statistics

Promensencen
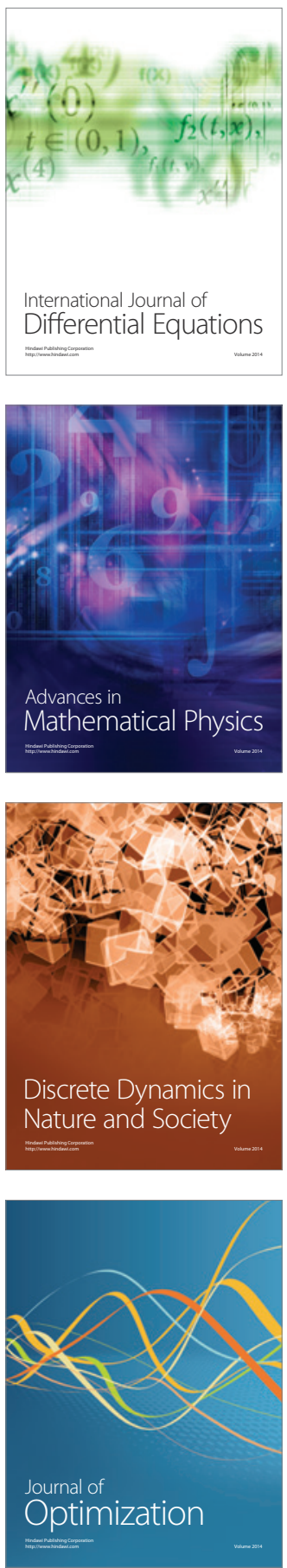